\title{
Cryptic species within the wheat curl mite Aceria tosichella (Keifer) (Acari: Eriophyoidea), revealed by mitochondrial, nuclear and morphometric data
}

Author(s): Anna Skoracka, Lechosław Kuczyński, Renata Santos de Mendonça, Mirosława Dabert, Wiktoria Szydło, Danuta Knihinicki, Graciela Truol and Denise Navia

Source: Invertebrate Systematics, 26(4):417-433.

Published By: CSIRO Publishing

URL: http://www.bioone.org/doi/full/10.1071/IS11037

BioOne (www.bioone.org) is a nonprofit, online aggregation of core research in the biological, ecological, and environmental sciences. BioOne provides a sustainable online platform for over 170 journals and books published by nonprofit societies, associations, museums, institutions, and presses.

Your use of this PDF, the BioOne Web site, and all posted and associated content indicates your acceptance of BioOne's Terms of Use, available at www.bioone.org/page/terms_of_use.

Usage of BioOne content is strictly limited to personal, educational, and non-commercial use. Commercial inquiries or rights and permissions requests should be directed to the individual publisher as copyright holder. 


\title{
Cryptic species within the wheat curl mite Aceria tosichella (Keifer) (Acari : Eriophyoidea), revealed by mitochondrial, nuclear and morphometric data
}

\author{
Anna Skoracka ${ }^{\mathrm{A}, \mathrm{G}}$, Lechosław Kuczyński ${ }^{\mathrm{B}}$, Renata Santos de Mendonça ${ }^{\mathrm{C}}$, \\ Mirosława Dabert ${ }^{\mathrm{D}}$, Wiktoria Szydło ${ }^{\mathrm{A}}$, Danuta Knihinicki ${ }^{\mathrm{E}}$, Graciela Truol ${ }^{\mathrm{F}}$ \\ and Denise Navia ${ }^{\mathrm{C}}$ \\ A Department of Animal Taxonomy and Ecology, Institute of Environmental Biology, Faculty of Biology, \\ Adam Mickiewicz University, Umultowska 89, 61-614 Poznań, Poland. \\ ${ }^{B}$ Department of Avian Biology and Ecology, Institute of Environmental Biology, Faculty of Biology, \\ Adam Mickiewicz University, Umultowska 89, 61-614 Poznań, Poland. \\ ${ }^{C}$ Embrapa Recursos Genéticos e Biotecnologia, Parque Estação Biológica, final W5 Norte, Cx. Postal 02372, \\ 70.770-917, Brasilia, Brazil. \\ DMirosława Dabert, Molecular Biology Techniques Laboratory, Faculty of Biology, Adam Mickiewicz University, \\ Umultowska 89, 61-614 Poznań, Poland. \\ ${ }^{E}$ NSW Department of Primary Industries, Agricultural Scientific Collections Unit, Orange Agricultural Institute, \\ 1447 Forest Road, Locked Bag 6006, Orange, NSW 2800, Australia. \\ ${ }^{F}$ Graciela Truol, Instituto de Fitopatología y Fisiología Vegetal, Instituto Nacional de Tecnología Agropecuaria, \\ Camino 60 cuadras km 5\%1/2, Cárcano, X5020ICA Córdoba, Argentina. \\ ${ }^{\mathrm{G} C}$ Corresponding author. Email: anna.skoracka@amu.edu.pl
}

\begin{abstract}
The wheat curl mite (WCM), Aceria tosichella (Keifer, 1969), is one of the primary pests of wheat and other cereals throughout the world. Traditional taxonomy recognises WCM as a single eriophyoid species; however, a recent study suggested that two genetic lineages of WCM in Australia might represent putative species. Here, we investigate WCM populations from different host plants in Australia, South America and Europe and test the hypothesis that WCM is, in fact, a complex of cryptic species. We used morphological data in combination with nucleotide sequences of the mitochondrial cytochrome $c$ oxidase subunit I (COI) and nuclear D2 region of 28S rDNA and internal transcribed spacer region (ITS1, ITS2) sequences. The molecular analyses did not support the monophyly of $A$. tosichella because the outgroup $A$. tulipae (Keifer, 1938) is grouped within WCM. The molecular datasets indicated the existence of distinct lineages within WCM, with the distances between lineages corresponding to interspecific divergence. Morphological analyses failed to clearly separate WCM populations and lineages, but completely separated $A$. tulipae from $A$. tosichella. The results suggest that what has been recognised historically as a single species is, in fact, a complex of several genetically isolated evolutionary lineages that demonstrate potential as cryptic species. Hence, their discrimination using solely morphological criteria may be misleading. These findings are particularly significant because of the economic importance of WCM as a direct pest and vector of plant viruses.
\end{abstract}

Received 25 September 2011, accepted 21 August 2012, published online 27 November 2012

\section{Introduction}

Speciation is not necessarily accompanied by morphological differentiation. The consequence is the existence of species complexes, which are genetically isolated lineages that are indistinguishable on the basis of morphological criteria alone. Such species are usually cryptic to human perception because of the lack of conspicuous morphological differences, but they may differ in physiological, behavioural and ecological traits (Calcagno et al. 2010; Henry and Wells 2010). The advent of rapid DNA sequencing technologies has revealed that morphologically static cladogenesis (i.e. the diversification of new species without morphological change) is unexpectedly common and has highlighted cryptic diversity in almost all taxonomic groups (e.g. Hansen et al. 2001; Pfenninger and Schwenk 2007; Astrin and Stüben 2008; Blanquer and Uriz 2008; Halt et al. 2009; Spencer et al. 2009; Jesse et al. 2010). Cryptic species are especially prevalent within groups of organisms that utilise other organisms for survival, such as parasites, parasitoids and herbivores (e.g. Drés and Mallet 2002; Bickford et al. 2007; Desneux et al. 2009). Some genetic analyses 
have revealed that presumed polyphagous taxa are, in fact, complexes of cryptic species that are specialised to different hosts (e.g. Drés and Mallet 2002; Hebert et al. 2003; Blair et al. 2005; Stireman et al. 2005; Smith et al. 2006; Rach et al. 2008; Skoracka and Dabert 2010). The results of these molecular tests have often been in contradiction with traditional taxonomy (Hebert et al. 2004).

The discrimination between cryptic species is not only important for the purpose of $\alpha$-taxonomy but also fundamental for understanding the processes of speciation, biodiversity, phylogeography, evolutionary theory and ecological interactions. Such discrimination is also crucial for the development of effective conservation strategies (Bickford et al. 2007). Moreover, the misidentification of medically and economically important species that belong to cryptic complexes may have serious negative implications, such as leading to inappropriate diagnoses of parasites and pathogens and ineffective control strategies for crop pests and invasive species (Armstrong and Ball 2005; Pringle et al. 2005; Bickford et al. 2007).

Among the economically important organisms in agriculture and forestry around the world, obligatory phytophagous eriophyoid mites (Acari : Eriophyoidea) have great impact as direct plant pests, plant pathogen vectors and invasive species (Lindquist et al. 1996; Navia et al. 2010). However, the taxonomy of this group currently relies upon morphological traits (Lindquist et al. 1996). The economic significance of eriophyoid mites is increasing worldwide: a large number of species have reached a permanent pest status for certain crops, and many species represent a quarantine threat for several countries (Duso et al. 2010). The accurate identification of eriophyoid mites is necessary for implementing optimal control and risk mitigation strategies. The small size of eriophyoid species, their structural simplicity and their limited number of diagnostic traits (which are often variable and overlapping among different taxa) often lead to misdiagnoses that can impair both the systematics of this group and agricultural strategies (Lindquist et al. 1996). Other approaches apart from morphological identification, such as ecological, behavioural or genetic methods, are scarcely employed for the identification of Eriophyoidea. Currently, more than 4000 species have been described (Amrine 2003), although estimates suggest that only $1.6-8 \%$ of the real eriophyoid fauna have been discovered (Amrine et al. 2003). Recent evidence from molecular studies suggests that cryptic speciation within this group may be far more common than previously realised (Carew et al. 2009; Skoracka and Dabert 2010); thus, the species diversity of this group may be much greater than is currently understood.

One of the most notable species among mites causing losses in cereal production is the eriophyoid Aceria tosichella (Keifer 1969), commonly known as the wheat curl mite (WCM). The WCM has been reported as one of the major pests of wheat and other cereals (e.g. sorghum, barley, corn, oats, rye, pearl millet) throughout the world (Oldfield and Proeseler 1996; Styer and Nault 1996). Direct damage symptoms owing to the feeding habits of the WCM include the discolouration, curling and rolling of leaves and abnormal leaf development and stunting of plant growth (Jeppson et al. 1975). Yield losses in wheat crops as a result of injuries caused by high mite infestations can reach $30 \%$ (Harvey et al. 2002). However, the primary impact of the
WCM is its ability to transmit plant viruses (Oldfield and Proeseler 1996). Wheat streak mosaic virus, vectored by A. tosichella, is the major pathogen of wheat, causing yield losses in North America, Europe, the Middle East, Oceania and Asia (Oldfield and Proeseler 1996; Sánchez-Sánchez et al. 2001; French and Stenger 2003). During the most recent decade, the WCM has become invasive, and both the mite and the virus have been detected in Australia and South America, seriously affecting primary wheat production areas (Halliday and Knihinicki 2004; Murray et al. 2005; Navia et al. 2006; Castiglioni and Navia 2010). Another virus transmitted by the WCM is Wheat mosaic virus (Hadi et al. 2011), and losses due to corn infestation by this pathogen in some regions of North America have been estimated at $\sim 75 \%$ (AQIS 2000). Other plant diseases associated with $A$. tosichella are Wheat spot mosaic virus (Jeppson et al. 1975), Brome streak mosaic virus (Stephan et al. 2008) and Triticum mosaic virus (Seifers et al. 2008, 2009).

Traditional taxonomy recognises $A$. tosichella as a single eriophyoid species that inhabits a wide range of graminaceous host plants. Approximately 80 grass species (e.g. cereals, pasture grasses, weeds) in 48 genera of Poaceae have been recorded as its hosts (Navia et al. in press). Most eriophyoid species are highly host specific, being restricted to a single host species. Thus, A. tosichella is one of the few exceptions among eriophyoid species, when the pattern of host-plant utilisation is taken into account. Since most information about potential host plants for A. tosichella has been based on accidental sampling (Skoracka et al.2010), such an unusually wide level of host specificity in this species is worthy of closer inspection. The need for evidencebased knowledge to demonstrate whether the WCM is indeed a single species with a broad host range, or whether it, in fact, represents a complex of closely related species that are specialised to particular host plants is obvious. The need for this research has become even more apparent recently, as molecular markers have indicated that $A$. tosichella in Australia consists of at least two separate lineages that may represent putative species (Carew et al. 2009).

We decided to explore this query further in detail, which included the study of WCM populations from different host plants and diverse continents. Our aims were to assess the levels of morphological and genetic variation within the WCM. Specifically, we intended to answer the following questions: (1) Are there any genetically isolated lineages within the WCM? and (2) Can these lineages be distinguished morphologically? To clarify the WCM boundaries, we compared morphological data with nucleotide sequences from mitochondrial cytochrome $c$ oxidase subunit I (COI) and the nuclear D2 region of $28 \mathrm{~S}$ rDNA, and internal transcribed spacer regions (ITS1, ITS2).

\section{Material and methods}

\section{Sampling}

The study included 25 populations of Aceria tosichella collected from various locations in Australia, South America (Argentina and Brazil) and Europe (France and Poland) (Table 1). Mites were collected from six grass species (Poaceae), including an economically important wheat (Triticum aestivum L.) and five 


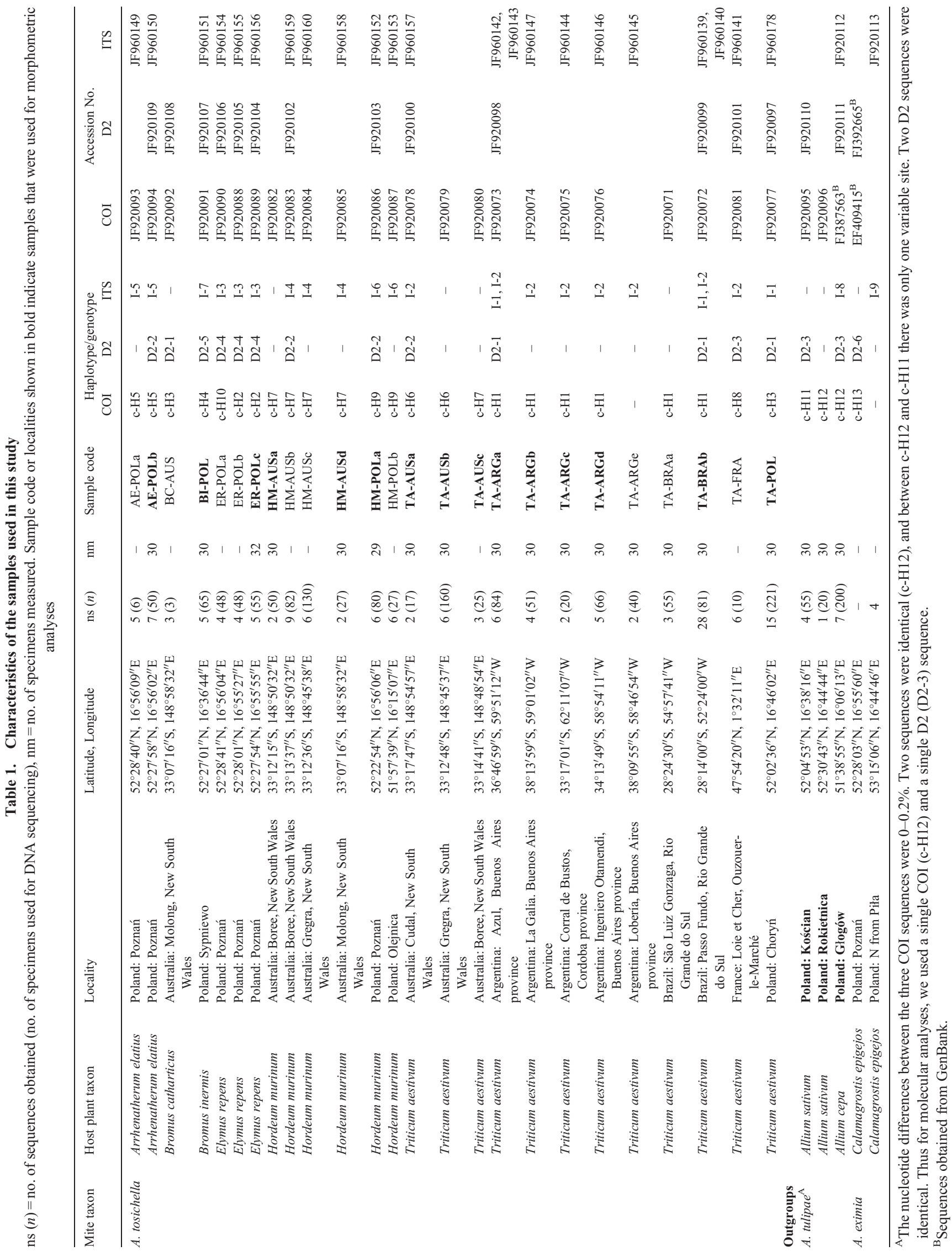


wild-growing species: oat-grass (Arrhenatherum elatius (L.) Beauv. ex Presl \& Presl), rescuegrass (Bromus catharticus Vahl), smooth brome (Bromus inermis Leyss.), quackgrass (Elymus repens (L.) Gould) and wall barley (Hordeum murinum L.; two subspecies: $H$. murinum subsp. murinum from Poland and $H$. murinum subsp. leporinum from Australia). Aceria eximia Sukhareva from the grass wood small reed (Calamagrostis epigejos (L.) Roth, Poaceae) and Aceria tulipae (Keifer) from garlic (Allium sativum L.) and onion (Allium cepa L.) (Alliaceae) were chosen as outgroups in the molecular analyses (Table 1). A. eximia is restricted to a single host plant species, $C$. epigejos, and specimens of this mite species were identified on the basis of the original and supplementary descriptions published by Sukhareva (1983) and Skoracka (2004), respectively. The traits that distinguish this species are the unique sculpture of the prodorsal shield (median line absent, admedian lines on rear half of shield, I and II submedian lines forming rhomb-like figures) and rounded ventral microtubercles. A. tulipae, although morphologically similar to A. tosichella, is restricted to plants belonging to the Alliaceae family and does not attack or survive on grasses. For our purposes, we used specimens of $A$. tulipae that were maintained in laboratory conditions for several weeks and identified on the basis of the original description by Keifer (1938). The traits that distinguish this species are the sculpture of the prodorsal shield (median line present, admedian lines complete, arched II submedian lines on posterior) and conical ventral microtubercles.

Grass samples collected in the field were transported to the laboratory for further examination. A single grass sample consisted of 10-20 grass shoots of a given plant species that was collected from a given locality. Subsequently, two methods of collecting mite specimens were applied: (1) the direct inspection of grass shoots under the stereomicroscope or (2) a washing technique as described by de Lillo (2001). Bulbs of onion and garlic were inspected directly under the stereomicroscope. Mites obtained from a specific host plant species and locality were regarded as a single population for analysis, hereafter referred to as a 'sample' (see sample codes in Table 1). The collected mite specimens were placed either in an eppendorf tube with absolute ethyl alcohol or directly into $180 \mu \mathrm{L}$ of ATL buffer (Qiagen GmbH, Hilden, Germany) and labelled for the purpose of molecular analysis. The numbers of individuals per tube varied from 1 to 40 . For the purpose of morphometric analysis, mite specimens were mounted onto microscope slides. The samples were collected between 2004 and 2009 .

\section{Molecular study}

\section{DNA extraction, amplification and sequencing}

Specimens that were preserved in ethyl alcohol were transferred to $180 \mu \mathrm{L}$ of ATL buffer before isolation. DNA was isolated from 1-40 specimens using a non-destructive method described by Dabert et al. (2008) or following the protocol described by Navia et al. (2005), except that RNA was not used as a carrier. To eliminate the concern about possible multiple operational taxonomic units within DNA samples extracted from multiple specimens we took the following precautions: (1) each population sample (if possible) was divided into (at least) two distinct parts and then independently subjected to the analysis, (2) DNA sequences obtained for particular samples were tested for homogeneity and compared (if possible) with sequences received for a single specimen, (3) heterogeneous sequences were discarded from the analysis, (4) no polymorphic sites were found in the analysed sequences.

Details about the number of specimens used for DNA extraction and the sequences obtained and analysed for a given sample are presented in Table 1 and in Supplemental Table 1. The slide-mounted specimens resulting from this non-destructive method were identified as $A$. tosichella and are stored in the reference collections of the Department of Animal Taxonomy and Ecology, AMU, Poznań, Poland.

We amplified a fragment of the cytochrome $c$ oxidase subunit I (COI) gene (DNA barcode region chosen by the Consortium for the Barcode of Life (http://barcoding.si.edu) with the degenerate primers bcdF01 (CATTTTCHACTAAYC ATAARGATATTGG) and bcdR04 (TATAAACYTCDGGAT GNCCAAAAAA) (Dabert et al. 2010). PCRs were conducted in $25 \mu \mathrm{L}$ reaction volumes containing a $1 \times$ reaction buffer (Fermentas, Vilnius, Lithuania), $1.5 \mathrm{~mm} \mathrm{MgCl}_{2}, \quad 0.1 \mathrm{~mm}$ dNTPs, $0.5 \mu \mathrm{M}$ of each primer, $1.25 \mathrm{U}$ Taq polymerase (Allegro, Novazym, Poznań, Poland) and $5 \mu \mathrm{L}$ of DNA template using a thermocycling profile of one cycle of $3 \mathrm{~min}$ at $96^{\circ} \mathrm{C}$ followed by 35 steps of $10 \mathrm{~s}$ at $95^{\circ} \mathrm{C}, 30 \mathrm{~s}$ at $50^{\circ} \mathrm{C}$, and $1 \mathrm{~min}$ at $72^{\circ} \mathrm{C}$, with a final step of $5 \mathrm{~min}$ at $72^{\circ} \mathrm{C}$.

Amplification of the D2 region in 28S rDNA was performed with the primers f1230 (Skoracka and Dabert 2010) and D1D2rev4 (Sonnenberg et al. 2007) as described above, except for the time of extension, which was $2 \mathrm{~min}$ at $72^{\circ} \mathrm{C}$. The primers defined in the $18 \mathrm{~S}$ and $28 \mathrm{~S}$ regions corresponded to nucleotides 1220-1250 and 4060-4079, respectively, of the Drosophila melanogaster rRNA gene cluster (GenBank accession number M21017). The amplicons were used for direct sequencing of the D2 region using primers D1D2fw2 and D1D2rev4 (Sonnenberg et al. 2007).

A nuclear region including ITS1 + 5.8S + ITS2 (a fragment of $\sim 900 \mathrm{bp}$ ) was amplified using the forward and reverse primers $18 \mathrm{~S}$ and $28 \mathrm{~S}$ as described in Navia et al. (2005). The primers defined in the $18 \mathrm{~S}$ and $28 \mathrm{~S}$ regions corresponded to nucleotides 1939-1963 and 3318-3338, respectively, of the Drosophila melanogaster rRNA gene cluster (GenBank accession number $\mathrm{M} 21017)$. PCRs were conducted in $25 \mu \mathrm{L}$ reaction volumes containing a $10 \times$ reaction buffer $(2.5 \mu \mathrm{L})$ (Qiagen, Brazil), $2.5 \mu \mathrm{L} \mathrm{MgCl}_{2}$ (25 mM), $0.2 \mu \mathrm{L}$ BSA (10 $\mathrm{mg} \mathrm{mL}^{-1}$ Biolabs), $14.05 \mu \mathrm{L}$ water, $2.5 \mu \mathrm{L}$ dNTP $(0.25 \mathrm{~mm}$ of each base $), 0.5 \mu \mathrm{M}$ of each primer, $0.25 \mathrm{un} / \mu \mathrm{L}$ Taq polymerase (Qiagen, Brazil) and $2 \mu \mathrm{L}$ of DNA template using a thermocycling profile of one cycle of $4 \mathrm{~min}$ at $94^{\circ} \mathrm{C}$ followed by 35 cycles of $30 \mathrm{~s}$ at $94^{\circ} \mathrm{C}, 30 \mathrm{~s}$ at $50^{\circ} \mathrm{C}$, and $1 \mathrm{~min}$ at $72^{\circ} \mathrm{C}$.

After amplification, $5 \mu \mathrm{L}$ of the PCR reaction was analysed by electrophoresis on a $1 \%$ agarose gel. Samples containing visible and single bands were directly sequenced in both directions using $1 \mu \mathrm{L}$ of the PCR reaction and 50 pmoles of the corresponding sequencing primer. Sequencing was performed with BigDye Terminator v3.1 on an ABI Prism 3130XL or 3730 Analyzer (Applied Biosystems, Foster City, 
CA, USA). Trace files were checked and edited using MEGA5 (Tamura et al. 2011).

\section{Sequence and phylogenetic analyses}

The COI and D2 sequences were aligned using ClustalW as implemented in MEGA5 (Tamura et al. 2011) with default gapweighting parameters and were then manually adjusted. Alignment of the COI sequences was confirmed by translating the aligned DNA into amino acids using GeneDoc ver. 2.7.000 (Nicholas and Nicholas 1997). ITS sequences were aligned using the ClustalW Multiple alignment procedure (Thompson et al. 1994) implemented in BIOEDIT ver. 7.0.4 (Hall 1999).

The overall and pairwise distance between nucleotide sequences, as well as the within- and among-clade distances, were calculated using Kimura's 2-parameter (K2P) model (Kimura 1980), with codon positions included $1 \mathrm{st}+2 \mathrm{nd}+3 \mathrm{rd}$ and with pairwise deletion of gap. Standard error estimates were obtained by a bootstrap procedure (1000 replicates). All of the above analyses were conducted using MEGA5 (Tamura et al. 2011).

The best-fit models of nucleotide substitution were selected in jModelltest ver. 0.1.1 (Guindon and Gascuel 2003; Posada 2008) on the basis of likelihood scores for 88 different models and both the Akaike information criterion (AIC) and Bayesian information criterion (BIC). For the $\mathrm{COI}$ dataset, $\mathrm{HKY}+\mathrm{I}+\mathrm{G}$ was chosen as the model for both the maximum-likelihood (ML) and Bayesian inference (BI) analyses, where the proportion of invariable sites $(I)=0.5840$ and the gamma distribution shape parameter $(G)=0.169$. The estimated base frequencies were: $A=0.2152$, $\mathrm{C}=0.1805, \mathrm{G}=0.1582$ and $\mathrm{T}=0.4460$. For the $\mathrm{D} 228 \mathrm{~S}$ rDNA dataset, the K80 model was selected according to BIC, and the TIM3 model was chosen according to AIC. The base frequencies were: $\mathrm{A}=0.2036, \mathrm{C}=0.2178, \mathrm{G}=0.3002$ and $\mathrm{T}=0.2783$. For the ITS dataset, the GTR + G nucleotide substitution model was implemented in the ML phylogenetic analysis with the following parameters: the base frequencies were empirical, the proportion of invariable sites was 0 , and the gamma distribution shape parameter $=0.412$.

Neighbour-joining (NJ) analyses were performed with a K2P model using MEGA5, and with statistical supports in the recovered trees estimated using non-parametric bootstrapping ( $n=1000$ replicates). ML analyses were performed using the online version of PhyMl 3.0 (Guindon et al. 2010) (available at: http://www.atgc-montpellier.fr/phyml/). Analyses were set to optimise branch lengths, and to search tree topologies using the nearest-neighbour interchange algorithm. For NJ analysis a bootstrap procedure (1000 replicates) was performed, and for ML analysis the Approximate Likelihood Ratio Test (aLRT: Anisimova and Gascuel 2006) was performed. MrBayes ver. 3.2 (Ronquist and Huelsenbeck 2003) was used to estimate phylogenetic relationships by BI. For each dataset, two independent runs were performed, and each consisted of two chains with the number of generations developed until the average standard deviation of split frequencies was less than 0.01 . A 50\% majority consensus tree with posterior probability values had been composed out of the obtained trees, with exclusion of the initial $25 \%$ of trees produced.
The COI and D2 sequences were sequenced from the same mite individuals whereas the ITS sequences came from different mite individuals, though they originated from the same sample (mite population). For the combined analysis COI, the D2 and ITS sequences were concatenated for the mite populations. All sequences have been deposited in GenBank under the accession numbers indicated in Table 1.

\section{Morphometric study}

Sample codes of the WCM populations studied morphologically are shown in bold in Table 1 (there were 15 populations). The mite specimens obtained from plants by direct examination or by a washing technique were mounted on slides using a standard protocol (Amrine and Manson 1996). The identification of A. tosichella was subsequently confirmed with the description by Keifer (1969). Thirty to 32 females in good condition were randomly selected from each population and examined in the dorsoventral position with the aid of a phase-contrast microscope. The following 38 morphological traits were measured on each individual according to Amrine and Manson (1996): total body length; chelicerae length; gnathosoma length; prodorsal shield length and width; number of dorsal annuli and ventral annuli; genital shield length and width; number of striations on the epigynium; lengths of the propodosomal and opisthosomal setae $s c, d$, e and $f$; length of the genital setae $(3 a)$; distances between the propodosomal and opisthosomal setae $s c, d$, e and $f$; distance between the genital setae $(3 a)$; distances between the coxal setae $1 b, 1 a$ and $2 a$; lengths of the segments and setae of leg I and leg II: tibiae I and II, tarsi I and II, solenidia I and II, empodia I and II, genual setae $l^{\prime}$ I and II, tibial seta $l^{\prime}$ I, tarsal setae I and II: $f t^{\prime}$ and $f t^{\prime}$.

Multivariate statistical analyses were performed on the abovementioned 38 quantitative variables. First, principal components analysis (PCA) was applied to reveal any discontinuities in morphological variation among the specimens originating from different hosts and different regions. For this purpose, population morphological data were plotted in the space of principal components and labelled accordingly to their origin (hostcountry combination) and subsequently visually inspected for any clusters or gaps. Second, linear discriminant analysis (LDA) was applied using groups corresponding to genetic clades obtained by molecular analysis of the COI gene. LDA was performed to determine morphometric differences between the genetic clades. According to molecular analysis, A. tulipae clustered within $A$. tosichella populations; thus, specimens of A. tulipae (three populations) were included in the LDA analysis. The squared Mahalanobis distance between the mean vectors was then used for graphical presentation of morphological relationships between clades. All computations were made in R 2.11.1 (R Development Core Team 2010).

Voucher specimens of individual mites measured in the morphometric study are deposited in the following reference collections: Department of Animal Taxonomy and Ecology, AMU, Poznań, Poland; Unidade de Acarologia, Laboratório de Quarentena Vegetal, Embrapa Recursos Genéticos e Biotecnologia, Brasilia, Brazil; Agricultural Scientific Collections Unit (ASCU), NSW, Department of Primary Industries, Orange Agricultural Institute, Forest Road, Orange, NSW 2800, Australia. 


\section{Results}

Molecular analyses

\section{$\mathrm{COI}$ sequence diversity and phylogenetic analyses}

The final COI dataset consisted of 26 aligned sequences of 605 bps, representing 24 populations of A. tosichella and two outgroups. No insertions or deletions were found. In the alignment, $167(27.6 \%)$ sites were parsimony informative, and $195(32.2 \%)$ sites were variable. Among the variable sites, 169 $(86.7 \%)$ were in the third codon position, $24(12.3 \%)$ were in the first codon position, and one $(0.5 \%)$ was in the second codon position.

The average mean divergence over all the sequence pairs (including the outgroup taxa) was $13.0 \%$ (s.e. $=1.0$ ) and ranged from $0 \%$ to $19.7 \%$. The average mean divergence over the A. tosichella sequences was $12.1($ s.e. $=1.0)$ and ranged from $0 \%$ to $18.6 \%$.

Ten haplotypes were identified from 24 COI sequences of A. tosichella with no clear correspondence to the host plant species or geographic region. Haplotypes c-H3 and c-H7 were found at more than one host plant species or sampling site: wheat in Poland and rescuegrass in Australia, and wheat and wall barley in Australia, respectively. Two different haplotypes (c-H2 and c-H10) were observed among the three populations of quackgrass in Poland (Table 1, Fig. 1). The average divergence among the A. tosichella haplotypes was $13.6 \%($ s.e. $=1.0)$ and ranged from $0.2 \%$ to $18.6 \%$. Pairwise comparison of the COI distances between the COI haplotypes in A. tosichella and congeneric Aceria species is presented in Table 2.

Ten haplotypes of $A$. tosichella clustered into seven well supported clades (Fig. 1). Variation within clades was minimal (the mean intraclade sequence divergence averaged $0.1 \%$ (s.e. $=0.2$ ) and ranged from $0 \%$ to $0.4 \%$ ) compared with variation between clades (average divergence was 14.5\% (s.e. $=1.5$ ) and ranged from $12.0 \%$ to $18.4 \%$ ). Pairwise comparison of the COI distances within and between the A. tosichella clades and between clades and congeneric Aceria species is presented in Table 3 .

General topologies of the phylogenetic trees inferred by NJ, ML analyses and BI of the nucleotide COI dataset were similar and consistently revealed the same structure of A. tosichella populations and two outgroups. Thus, only the

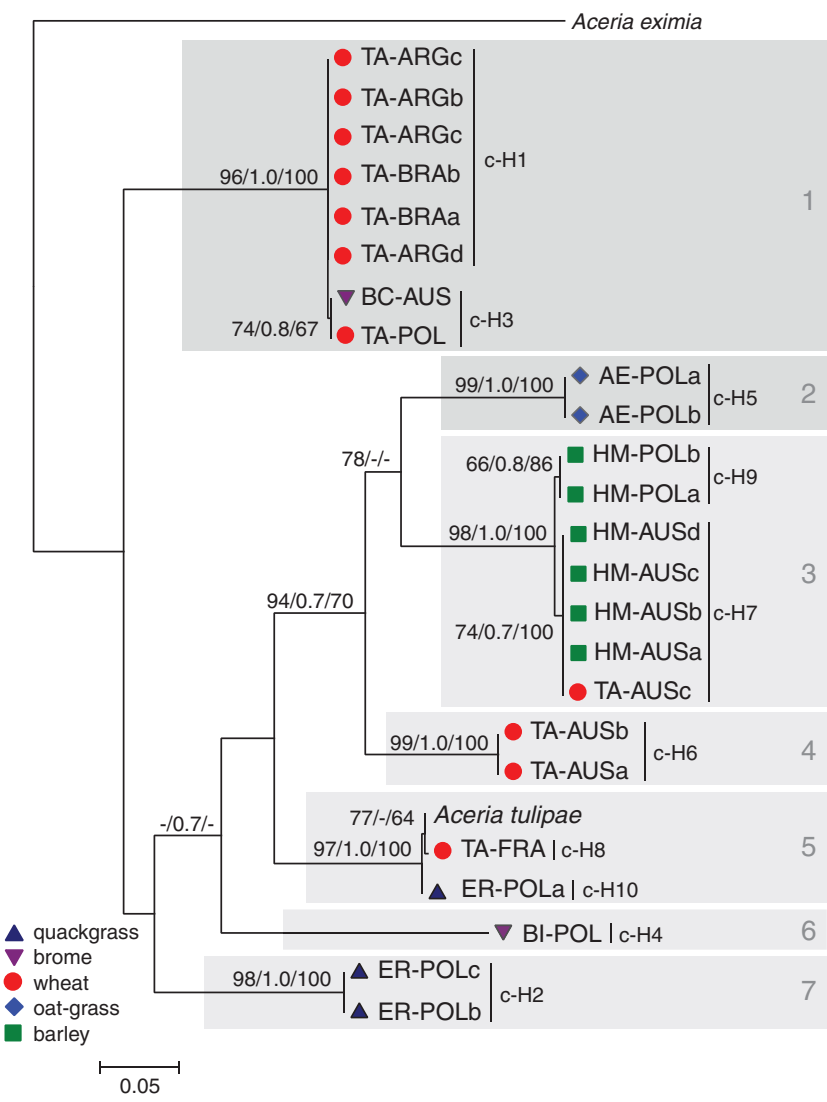

Fig. 1. Maximum-likelihood (ML) tree performed with $\mathrm{HKY}+\mathrm{I}+\mathrm{G}$ model of the cytochrome c oxidase subunit I sequences of Aceria eriophyoid mites with indication of COI haplotypes (labelled with 'c-H') and clades (indicated as grey boxes and numbered). Concordant trees were obtained by Bayesian inference (BI) and neighbour-joining (NJ) analyses, which produced the same topology in defining groups. Statistical supports indicate maximumlikelihood aLRT values/Bayesian posterior probabilities/neighbour-joining bootstraps. Only statistical supports greater than 60/0.6/60 are indicated above branches. Populations from different host plants are labelled.

ML tree is presented (Fig. 1). However, the resolution and statistical support were weak for most of the topology above the terminal clade level.

Table 2. Kimura 2-parameter distances (presented as percentages with standard error estimates in parentheses) between COI haplotypes within the Aceria tosichella complex and its outgroups

For a definition of the haplotype labels, see Fig. 1, Table 1 and the written text

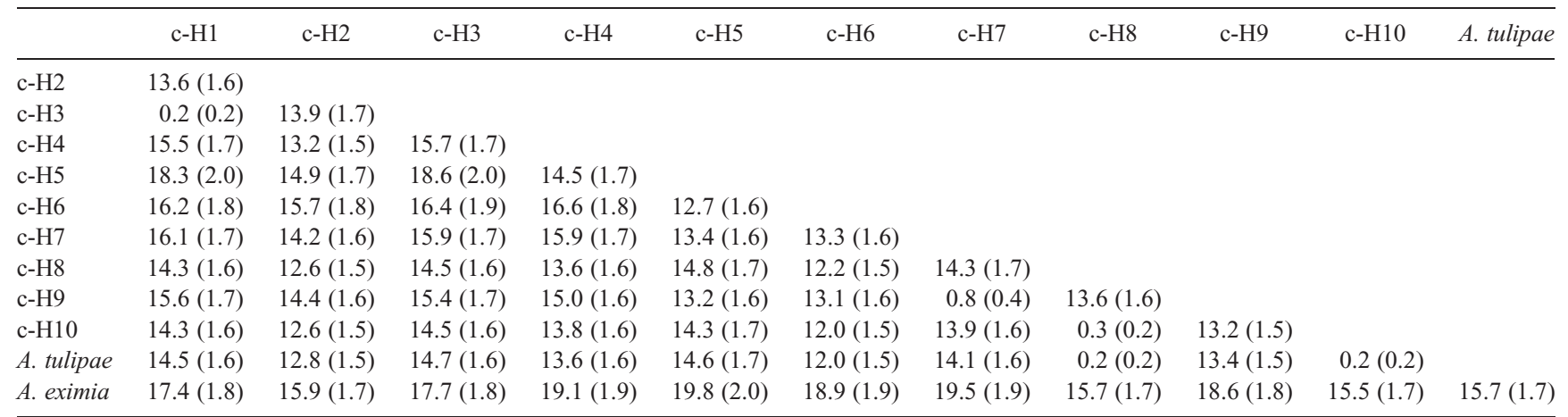


Table 3. Estimates of average evolutionary divergence (presented as percentages with standard error estimates in parentheses) over mtDNA COI sequence pairs within (bolded) and between clades of Aceria tosichella and the outgroup Aceria eximia

Analyses were conducted using the Kimura 2-parameter model. For a definition of each clade, see Fig. 1 and the written text

\begin{tabular}{|c|c|c|c|c|c|c|c|}
\hline & 1 & 2 & 3 & 4 & 5 & 6 & 7 \\
\hline 1 & $0.1(0.1)$ & & & & & & \\
\hline 2 & $18.4(2.0)$ & $0.0(0.0)$ & & & & & \\
\hline 3 & $15.9(1.7)$ & $13.4(1.5)$ & $0.4(0.2)$ & & & & \\
\hline 4 & $16.2(1.8)$ & $12.7(1.6)$ & $13.3(1.6)$ & $0.0(0.0)$ & & & \\
\hline 5 (with A. tulipae) & $14.4(1.7)$ & $14.6(1.7)$ & $13.9(1.6)$ & $12.0(1.5)$ & $0.2(0.1)$ & & \\
\hline 6 & $15.5(1.7)$ & $14.5(1.7)$ & $15.7(1.7)$ & $16.6(1.8)$ & $13.7(1.7)$ & $\mathbf{n} / \mathbf{c}$ & \\
\hline 7 & $13.7(1.7)$ & $14.9(1.7)$ & $14.2(1.6)$ & $15.7(1.8)$ & $12.6(1.5)$ & $13.2(1.5)$ & $0.0(0.0)$ \\
\hline A. eximia & $17.5(1.8)$ & $19.8(1.9)$ & $19.3(1.9)$ & $18.9(1.9)$ & $15.7(1.7)$ & $19.1(1.9)$ & $15.9(1.7)$ \\
\hline
\end{tabular}

The phylogenetic trees indicated that $A$. tosichella was not monophyletic, as $A$. tulipae grouped within the WCM. There was poor correspondence between the clades and host plants or geographic regions. Clade 3 comprised six barley-associated populations originating from Poland and Australia, and one wheat-associated population from Australia. Clade 1 included seven populations collected on wheat from Poland, Brazil and Argentina, and one population collected on rescuegrass from Australia. Clade 5 comprised one population collected on quackgrass from Poland, one wheat-associated population from France and the outgroup A. tulipae. However, Clade 2 was unique to tall oat-grass from Poland (Fig. 1).

Populations of $A$. tosichella collected on wheat from different countries appeared to be genetically variable. Populations collected from wheat in Brazil and Argentina clustered together with wheat-associated populations from Poland (Clade 1). Other populations from wheat in France and Australia hosted three different clades (Clades 3, 4 and 5). Quackgrass-associated populations from Poland were also variable and hosted two different clades (Clades 5 and 7) (Fig. 1).

There was high support ( 94 for ML, 0.7 for BI and $70 \%$ for NJ) for the monophyly of a cluster consisting of haplotypes found in oat-grass-associated populations from Poland, wheat-associated populations from Australia (Clades 2 and 4) and Clade 3, comprising haplotypes of barley-associated mites and another wheat-associated haplotype from Australia. Relationships between other clades were not supported (Fig. 1).

\section{D2 sequence diversity and phylogenetic analyses}

The nuclear data, including 511 positions for the D2 region of 28S rDNA, were obtained for $13 \mathrm{~A}$. tosichella populations and two outgroups ( $A$. tulipae and $A$. eximia). The average mean divergence over all sequence pairs (including the outgroup taxa) was $0.7 \%$ (s.e. $=0.1$ ) and ranged from $0 \%$ to $2.4 \%$. The average mean divergence over the $A$. tosichella sequences was 0.4 $($ s.e. $=0.2)$ and ranged from $0 \%$ to $0.7 \%$.

Thirteen sequences of $A$. tosichella were varied and represented five different genotypes (designated D2-1 through D2-5). Sequences D2-1 and D2-2 were associated with more than one host plant species or sampling site. The sequence D2-1 was found in wheat-associated populations in Poland and South America and in a population from rescuegrass in Australia. The genotype D2-2 was found in populations from wheat in Australia, wall barley in Australia and Poland and oat-grass in
Poland. The sequence from wheat in France represented the same genotype as the outgroup A. tulipae from onion in Poland (Table 1, Fig. 2). The average divergence among the five A. tosichella genotypes was $0.5 \%($ s.e. $=0.2)$ and ranged from $0.2 \%$ to $0.8 \%$. Pairwise comparison of the distances in the D2 region among the $A$. tosichella sequences and the outgroup is presented in Table 4.

Five D2 sequences of $A$. tosichella clustered into three clades (Fig. 2). Clades 1 and 2 were entirely homogenous, with a mean intraclade sequence divergence of $0 \%$, and the between-clade divergence for these two clades corresponding to the divergence between sequence variants. The mean intraclade divergence of Clade 3 was $0.14 \%$ (s.e. $=0.1$ ). The average divergence among the clades was the same as among the genotypes and ranged from $0.2 \%$ to $0.4 \%$. The distance between Clade 3 and Clades 1 and 2

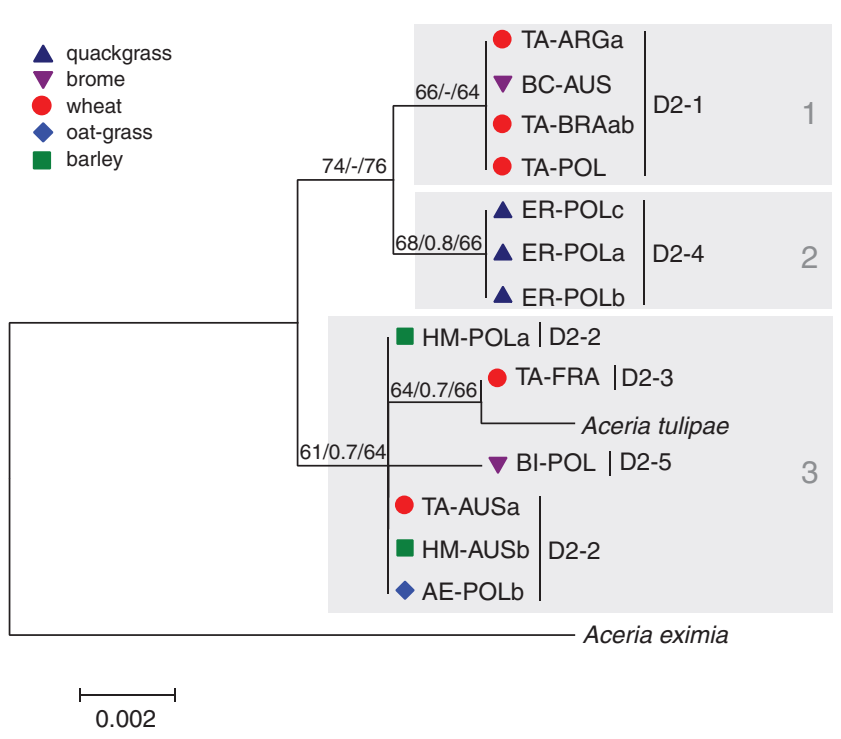

Fig. 2. Maximum-likelihood (ML) tree performed with TIM3 model of the 28S r-RNA subunit D2 sequences of Aceria eriophyoid mites with indication of D2 genotypes (labelled with 'D2-1' etc.) and three clades (indicated as grey boxes and numbered). Concordant trees were obtained by Bayesian inference (BI) and neighbour-joining (NJ) analyses, which produced the same topology in defining groups. Statistical supports indicate maximum-likelihood aLRT values/Bayesian posterior probabilities/neighbour-joining bootstraps. Only statistical supports greater than 60/0.6/60 are indicated above branches. Populations from different host plants are labelled. 
Table 4. Kimura 2-parameter distances (presented as percentages with standard error estimates in parentheses) between D2 genotypes within the Aceria tosichella complex and its outgroups

For a definition of the genotypes labels, see Fig. 2, Table 1 and the written text

\begin{tabular}{lccccc}
\hline & D2-1 & D2-2 & D2-3 & D2-4 & D2-5 \\
\hline D2-2 & $0.6(0.3)$ & & & & \\
D2-3 (with A. tulipae) & $0.8(0.4)$ & $0.2(0.2)$ & & & \\
D2-4 & $0.4(0.2)$ & $0.6(0.3)$ & $0.4(0.4)$ & & \\
D2-5 & $0.8(0.4)$ & $0.2(0.2)$ & $0.4(0.3)$ & $0.8(0.4)$ & \\
A. eximia & $2.2(0.6)$ & $2.0(0.6)$ & $2.2(0.6)$ & $2.2(0.7)$ & $2.2(0.7)$ \\
\hline
\end{tabular}

was $0.6 \%($ s.e. $=0.3)$, and the distance between Clade 1 and Clade 2 was $0.4 \%$ (s.e. $=0.2)$.

The general topologies of the phylogenetic trees obtained by the $\mathrm{NJ}$ and $\mathrm{ML}$ analyses and the $\mathrm{BI}$ approach of the $\mathrm{D} 2$ region dataset were consistent with each other; therefore, only the ML tree is presented (Fig. 2). The phylogenetic trees did not support monophyly of the WCM. Populations of A. tosichella formed three moderately supported clades: $\geq 61$ for ML, $\geq 0.7$ for BI (except Clade 1) and $\geq 64$ for NJ (Fig. 2). There was no general correspondence between the clades and host plants or geographic regions. Only Clade 2 grouped together populations collected from the same host plant and region; it comprised quackgrassassociated mites from Poland. Two other clades consisted of lineages representing populations from different host plants and regions. Clade 1 included genotypes found in wheat-associated populations from Poland, Brazil and Argentina and the rescuegrass-associated population from Australia, corresponding with Clade 1 on the COI tree. Clade 3 grouped genotypes found in four host plant species from Poland, Australia and France, as well as the outgroup of A. tulipae. Part of Clade 3 consisted of the D2-2 sequences that correspond with the cluster including Clades $2-4$ on the COI tree. There was a clear internal split within Clade 3 while the wheat-associated population from France with A. tulipae formed a moderately supported ( $64 \%$ for ML, 0.7 for $\mathrm{BI}$, and $66 \%$ for NJ) subclade. This subclade partially corresponds with Clade 5 on the COI tree (Figs 1,2).

\section{ITS sequence diversity and phylogenetic analyses}

Seven different ITS genotypes (designated I-1 through I-7) were identified among 71 sequences found in global $A$. tosichella populations. General topologies of the phylogenetic trees obtained by the $\mathrm{NJ}$ and $\mathrm{ML}$ analyses and the $\mathrm{BI}$ approach of the ITS region dataset were similar, and only the ML tree is shown (Fig. 3). The phylogenetic trees did not support monophyly of the WCM. Seven genotypes of $A$. tosichella clustered into two main clades that were highly supported. The second clade (with a support of $91 \%$ for ML and $93 \%$ for NJ) of clustered genotypes I-2, I-4, I-5 and I-6 included genotypes found in populations as follows: wheat from Argentina, Brazil, France and Australia; wall barley from Australia and Poland; oat-grass from Poland. This clade also included A. tulipae. The first clade (with 96\% support for ML, 1.0 for BI and $98 \%$ for NJ) of clustered genotypes I-1, I-3 and I-7 included sequences found in populations as follows: wheat from Argentina, Brazil and Poland; quackgrass and smooth brome from Poland. Within Clade 1, there were three well supported terminal clades: two sister clades, namely $1 \mathrm{~A}$

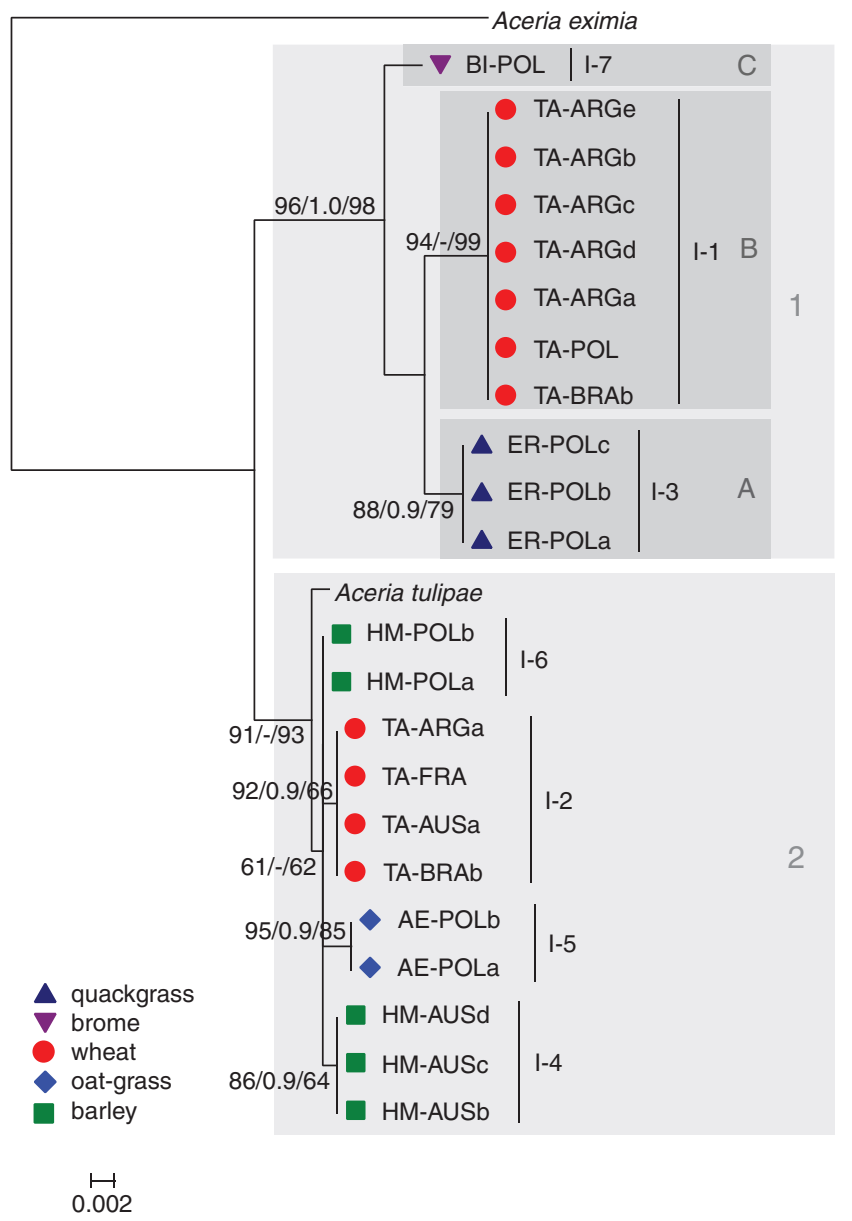

Fig. 3. Maximum-likelihood (ML) tree performed with GTR $+\mathrm{G}$ model of the ribosomal region ITS of Aceria eriophyoid mites with indication of ITS genotypes (labelled with 'I-1', etc.) and clades (indicated as grey boxes and numbered). Concordant trees were obtained by Bayesian inference (BI) and neighbour-joining (NJ) analyses, which produced the same topology in defining groups. Statistical supports indicate maximum-likelihood aLRT values/Bayesian posterior probabilities/neighbour-joining bootstraps. Only statistical supports greater than 60/0.6/60 are indicated above branches. Populations from different host plants are labelled.

comprising mites from quackgrass (which corresponds with Clade 2 on the $\mathrm{D} 2$ tree), and 1B comprising mites from wheat, and $1 \mathrm{C}$ comprising mites from smooth brome in Poland. Among the $A$. tosichella sequences collected on wheat, two genotypes (I-1 and I-2) were generated. The genotype I-1 was found in Argentina, Brazil and Poland, and the genotype I-2 was observed in Argentina, Brazil, France and Australia. In two South American populations (TA-ARGa and TA-BRAb) two copies of ITS sequences from each population were obtained (Table 1). The average divergence among $A$. tosichella ITS genotypes was $1.3 \%$ (s.e. $=0.3$ ) and ranged from $0.1 \%$ to $2.4 \%$. The divergence between the two main clades ( 1 and 2 ) was $2.2 \%($ s.e. $=0.5)$. The divergence within Clades 1 and 2 was $0.5 \%$ and $0.2 \%$, respectively. Pairwise comparison of ITS distances between $A$. tosichella genotypes and outgroups is presented in Table 5. 
Table 5. Kimura 2-parameter distances (presented as percentages with standard error estimates in parentheses) between ITS genotypes within the Aceria tosichella complex and its outgroups

For a definition of the genotypes labels, see Fig. 3, Table 1 and the written text

\begin{tabular}{lccccccc}
\hline & $\mathrm{I}-1$ & $\mathrm{I}-2$ & $\mathrm{I}-3$ & $\mathrm{I}-4$ & $\mathrm{I}-5$ & $\mathrm{I}-6$ & $\mathrm{I}-7$ \\
\hline $\mathrm{I}-2$ & $2.3(0.5)$ & & & & & & \\
$\mathrm{I}-3$ & $0.8(0.3)$ & $1.8(0.5)$ & & & & \\
$\mathrm{I}-4$ & $2.3(0.5)$ & $0.2(0.2)$ & $1.8(0.5)$ & & & \\
$\mathrm{I}-5$ & $2.4(0.5)$ & $0.4(0.2)$ & $1.9(0.5)$ & $0.4(0.2)$ & & & \\
$\mathrm{I}-6$ & $2.2(0.5)$ & $0.1(0.1)$ & $1.6(0.4)$ & $0.1(0.1)$ & $0.2(0.2)$ & & \\
$\mathrm{I}-7$ & $1.3(0.4)$ & $2.0(0.5)$ & $1.0(0.4)$ & $2.0(0.5)$ & $2.1(0.5)$ & $1.9(0.5)$ & \\
A. tulipae & $2.4(0.5)$ & $0.4(0.2)$ & $1.9(0.5)$ & $0.4(0.2)$ & $0.5(0.2)$ & $0.2(0.2)$ & $6(0.5)$ \\
A. eximia & $7.5(1.0)$ & $6.4(0.9)$ & $7.0(0.9)$ & $6.3(0.9)$ & $6.4(0.9)$ & $6.3(0.9)$ & $6.8(0.9)$ \\
\hline
\end{tabular}

\section{Combined analysis}

A combined analysis, which included unique variants of nucleotide sequences of the mitochondrial cytochrome $c$ oxidase subunit I, nuclear D2 region of 28S rDNA and both internal transcribed spacer (ITS1, ITS2) regions, supported the results of previous analyses indicating paraphyly of $A$. tosichella with respect to A. tulipae (Fig. 4). Strong support was provided for a sister relationships between A. tulipae and WCM from wheat in France. Although, two alternative copies of ITS genotypes were found in two South American populations from wheat (I-1 and I-2) (Table 1) all wheat-associated mites from Poland and South America formed a distinct, well supported clade. One quackgrassassociated population from Poland clustered with smooth brome-associated mites from Poland and was a sister clade to the former 'wheat' clade (although supports were poor). The other quackgrass-associated population from Poland (with different COI haplotype) formed a distinct lineage. Mites from wheat in Australia, oat-grass in Poland, and barley in Poland and Australia also formed a distinct and well supported clade. The two latter populations were the most similar to each other (Fig. 4).

\section{Morphometric analyses}

Of the total morphological variability, $91 \%$ was explained by three PCA components (70, 12 and $9 \%$ of total variance). There was an overlap of all populations in the space of principal components (Fig. 5); however, some populations appeared to form morphologically distinct clusters. This observation was especially true for wheat-associated mites from Argentina and Brazil, which formed a well defined and clumped group with relatively low morphological variability. This group could be separated by the second principal component, which can be interpreted as the ratio of the body shape and the length of the legs and setae. Other groups were more scattered, and there were no strong aggregations, albeit some patterns that arose. For instance, the first principal component, which reflects the size of the studied individuals, separated the brome-associated mites collected in Poland from the barley-associated mites from Australia (Fig. 5A). The third principal component separated oat-grass-associated mites in Poland from other populations (Fig. 5B).

Linear discriminant analysis (LDA) was performed on six groups of $A$. tosichella and one group of A. tulipae, corresponding to genetic clades obtained by molecular analysis of the COI gene (see Table 1). Overall, the classification accuracy (computed

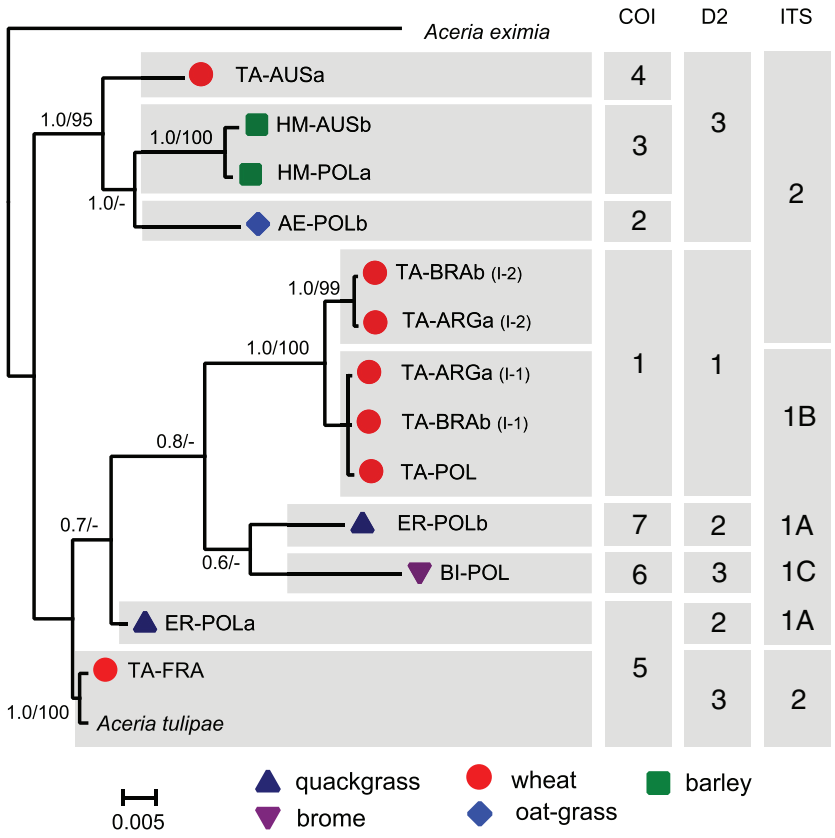

Fig. 4. Combined Bayesian inference (BI) analysis tree for Aceria eriophyoid mites calculated from the cytochrome $\mathrm{c}$ oxidase subunit I sequences (COI), 28S r-RNA subunit D2 sequences and ribosomal region ITS. A concordant tree was obtained by neighbour-joining (NJ) analysis, which produced the same topology. Statistical supports indicate Bayesian posterior probabilities/neighbour-joining bootstraps. Only statistical supports greater than $0.6 / 60$ are indicated above branches. Populations from different host plants are labelled. The congruity among the COI, D2 and ITS sequences is indicated as boxes on the right side of the tree. Numbers in boxes correspond to the clade numbers indicated in Figs $1-3$.

using leave-one-out cross-validation) was $95 \%$ (Table 6). The first linear discriminant (LD1) dominated the between-group variation $(\sim 59 \%)$ and completely separated A. tulipae from A. tosichella (Fig. 6A). A detailed analysis of the loadings structure (Table 7) suggests that this axis is attributed to the overall size of the mites that were studied. Mites possessing the 'tulipae' haplotype were much larger than mites with all other haplotypes. The second linear discriminant (LD2) differentiated wheat-associated clades from brome- and oat-grass-associated populations. Traits that discriminated these populations were linked to the epigynium, the shape of the body and the prodorsal shield, the proportion of the leg segments and setae 
(

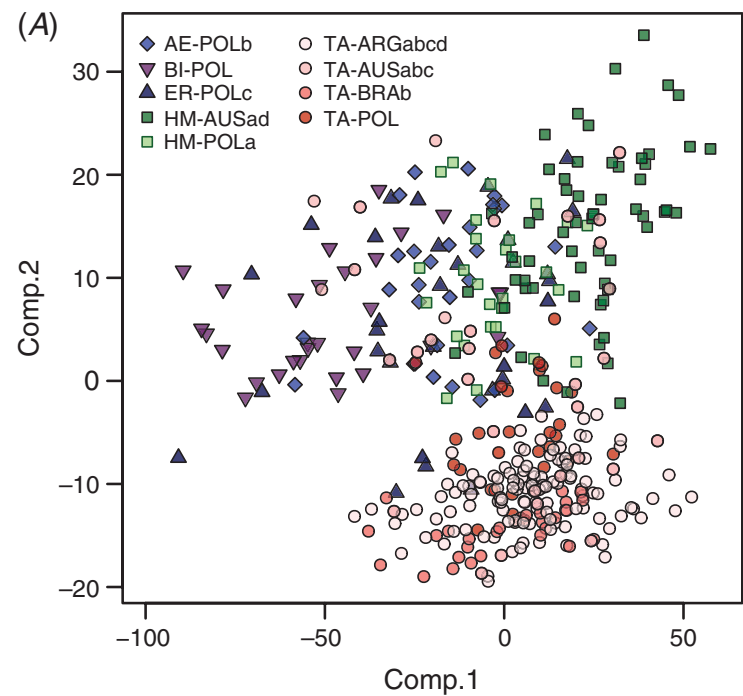

(B)

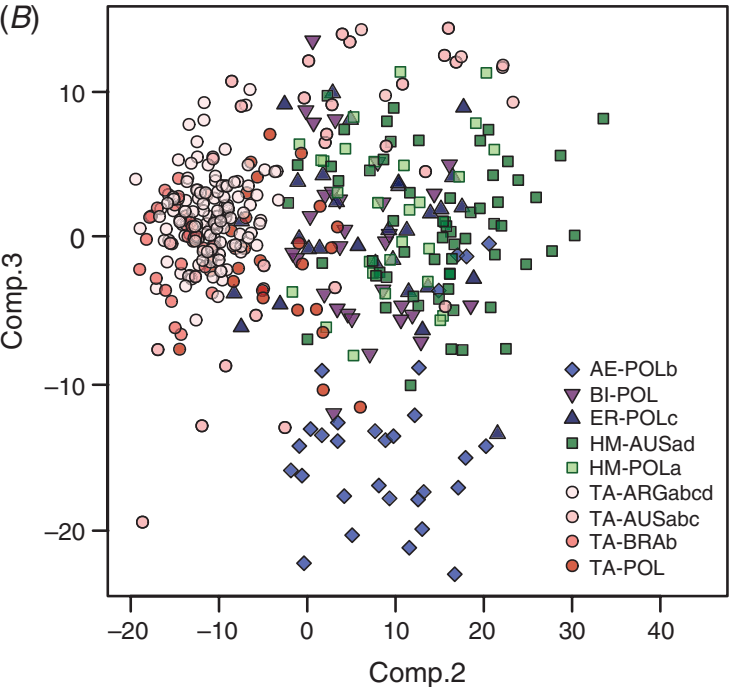

Fig. 5. First three principal components ( $A$, first and second; $B$, second and third) for morphometric data of Aceria tosichella populations. Populations originating from the same host and country were merged together. For populations labels see Table 1.

Table 6. Cross-validated confusion matrix for the linear discriminant analysis performed on morphometric data

The values are percentages of cases falling within each category. The 'tulipae' clade is the only group that can be perfectly classified (100\% of predictions are correct). The 'barley' clade has the worst classification accuracy (13.5\% of cases are classification errors). The number in parentheses next to the clade name corresponds to the numbers of the clade in Fig. 1

\begin{tabular}{lccccrrr}
\hline Prediction & Barley (3) & Brome (6) & Oat-grass (2) & $\begin{array}{c}\text { Reference } \\
\text { Quackgrass (7) }\end{array}$ & Tulipae (5) & Wheat1 (1) & Wheat2 (4) \\
\hline Barley (3) & 86.5 & 3.3 & 0.0 & 0.0 & 0.0 & 2.8 \\
Brome (6) & 3.4 & 96.7 & 0.0 & 0.0 & 0.0 & 0.0 \\
Oat-grass (2) & 2.2 & 0.0 & 93.3 & 0.0 & 0.0 & 0.0 & 0.0 \\
Quackgrass (7) & 0.0 & 0.0 & 6.7 & 96.9 & 0.0 & 0.0 & 0.0 \\
Tulipae (5) & 0.0 & 0.0 & 0.0 & 3.1 & 0.0 & 0.0 \\
Wheat1 (1) & 4.5 & 0.0 & 0.0 & 0.0 & 0.0 & 0.0 \\
Wheat2 (4) & 3.4 & 0.0 & 0.0 & & 0.0 & 0.0 \\
\hline
\end{tabular}

as well as the lengths of the opisthosomal setae. The greater the value of LD2, the more striations were found on the epigynium in conjunction with a less elongated body with fewer dorsal annuli, a longer and narrower prodorsal shield, shorter ventral setae, longer tibiae, empodia, genual and tibial setae, and shorter solenidia and tarsi with tarsal setae. Individuals from brome- and oat-grassassociated populations were characterised by greater values of LD2 in contrast to the wheat-associated mites (Fig. 6B). The third linear discriminant (LD3) separated both groups of wheatassociated mites, Clade 4 originating from Australia and Clade 1 from South America and Poland. This axis could also be used to distinguish the 'brome' Clade 6 from both 'oat-grass' and 'quackgrass' Clades (2 and 7, respectively) as presented in Fig. $6 B$. LD3 revealed that there was a contrast between the dorsal and ventral annuli, the width of the body measured by the distance between the ventral setae, the lengths of leg segments and setae, the shape of the prodorsal shield and the length of $s c$ setae. Specimens with greater values of this variable had a greater number of dorsal annuli with fewer ventral annuli. They also had a wider body, shorter leg segments and setae, a longer and narrower prodorsal shield and shorter sc setae.
Morphological relationships among clades were not concordant with the genetic relationships among the mtDNA COI clades (Fig. 7). Morphologically, mites from quackgrass were most similar to those from brome, and mites from oat-grass formed a sister group for them. Mites from barley were the most similar to A. tulipae, with mites from wheat in South America and Poland forming a sister group. Genetically, mites collected from oat-grass and those collected from wheat in Australia were the most similar, with mites from barley forming a sister group.

\section{Discussion}

\section{Genetic and morphological variation and species status} of WCM

Aceria tosichella was long considered to be a single species with a broad host range (Styer and Nault 1996; Amrine 2003). Our results, which are based on data collected from different host plants in three continents, are not in accord with the hitherto prevailing taxonomic data for this mite. Phylogenetic divergences based on mitochondrial and nuclear markers 

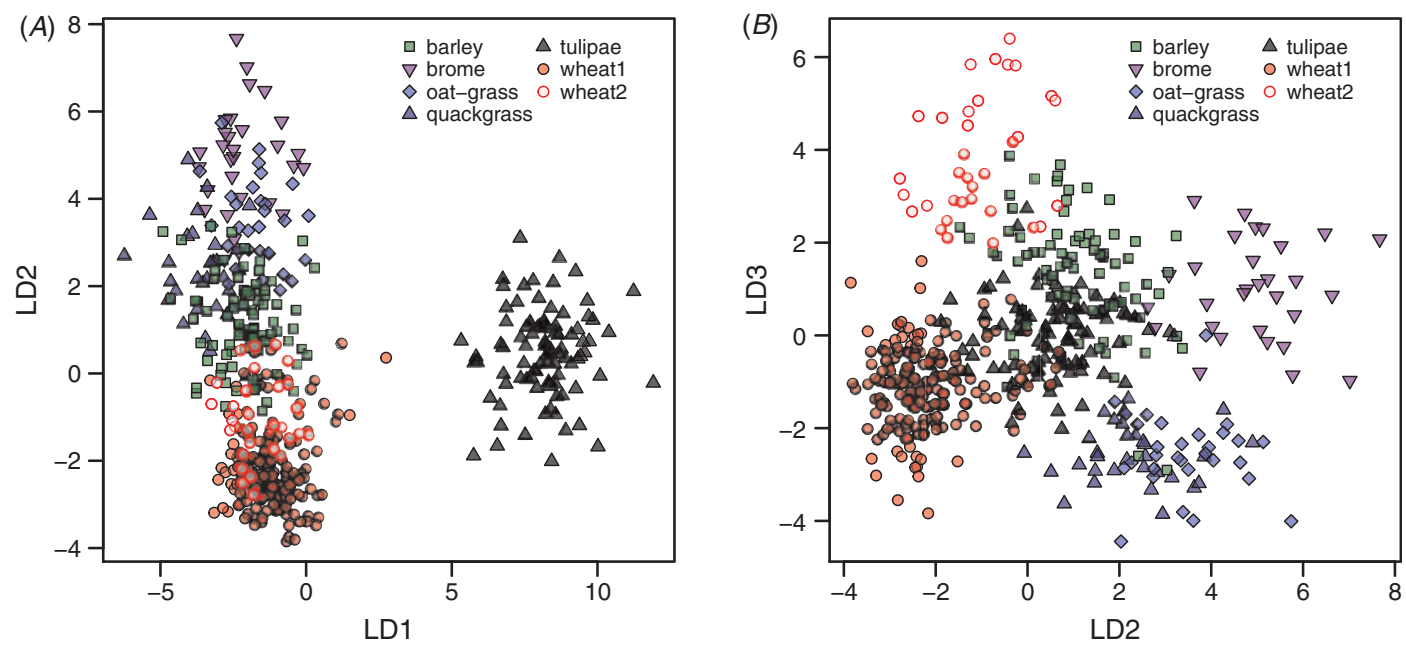

Fig. 6. First three linear discriminants ( $A$, first and second; $B$, second and third) for morphometric data of Aceria genetic clades.

and slight morphological differentiation between the studied populations suggest that the WCM consists of morphologically cryptic but genetically separated lineages. In addition, $A$. tulipae, a species chosen as the outgroup, did not form a sister group for A. tosichella in the molecular analyses. In contrast, on all trees, A. tulipae was found inside the A. tosichella complex. Such outcomes do not support the monophyly of the WCM; instead, it may be hypothesised that $A$. tulipae and $A$. tosichella belong to the same species complex. A. tulipae, described from tulip bulbs (Liliaceae), was thought to be morphologically very similar to A. tosichella. For many years, both species had been misidentified and the name $A$. tulipae had been applied to the WCM, especially by North American researchers until 1995 (Harvey et al. 1995a, 1995b). The LDA analysis performed in this study demonstrates that specimens of $A$. tulipae are, in fact, much larger than those of $A$. tosichella.

The present results indicate that A. tulipae belongs to one $A$. tosichella lineage (with very low intraclade distances) that strongly differs from other $A$. tosichella lineages. Unfortunately, we were unable to gather morphological data (not enough suitable specimens for morphometric analysis were available) for the WCM specimens originating from populations that clustered with $A$. tulipae on the COI-based tree (i.e. TA-FRA, ER-POLa). Thus, we could not analyse the morphological relationships between those populations. If such data were obtainable, two scenarios would have been possible. First, the WCM mites (that clustered with A. tulipae on COI-based tree) are morphologically similar to other WCM populations, and this similarity suggests that the effect of host-related phenotypic plasticity influences mite morphology. Second, WCM mites are morphologically similar to A. tulipae, and this similarity is suggestive of genetically dependent morphological variation. Undoubtedly, there is a need for more detailed genetic and ecological investigation that includes the examination of additional WCM and A. tulipae populations in order to resolve this problem. A. tulipae from Alliaceae appears to be more closely related to $A$. tosichella than to $A$. eximia from Poaceae (see the distances in Tables 2-5). Thus, A. tulipae and various WCM populations constitute a complex of species with various levels of genetic variation and well defined morphological differences between $A$. tulipae and the WCM.

The mitochondrial marker COI, which is widely used as a DNA barcode (Hebert et al. 2003), was the most variable of the three genes tested in this study. The divergences between the WCM clades (12.0-18.4\%) were almost as great as the distances between the WCM clades and the species $A$. eximia (15.9-19.8\%). Hebert et al. (2003) demonstrated a mean sequence divergence of $11.3 \%$ for more than 13000 comparisons of the COI sequences of congeneric species pairs of various animals. Values of COI intraspecific distances have ranged from $0.2 \%$ to $2.4 \%$ whereas interspecific distances have ranged from $4.9 \%$ to $18.9 \%$ in several species of mites (e.g. Anderson and Morgan 2007; Dabert et al. 2008; Tixier et al. 2008). COI nucleotide divergences among the ectoparasitic mite genus Dermanyssus ranged from 9\% to 18\% (Roy et al. 2010 ) and reached $17.8 \%$ between two water mite species (Martin et al. 2010). The divergences among the WCM clades found for the COI gene in this study are, therefore, comparable to the among-species variation that has been found in other mite taxa. The lack of overlap between intraclade and interclade COI divergence additionally argues for species delineation among clades of the WCM. Mitochondrial DNA mutates at a faster rate than nuclear DNA (Lynch et al. 2006), resulting in mitochondrial DNA becoming a convenient tool for phylogenetic exploration at a low taxonomic level (e.g. between closely related species). However, its mode of maternal inheritance can only reveal the presence of divergent maternal lineages and cannot confirm the existence of reproductive isolation between lineages, which is why we also included nuclear DNA.

Variation in the $\mathrm{D} 2$ region of 28SrRNA revealed the existence of three main lineages within the WCM (with one clade, viz. 3, reflecting unresolved polytomy of three lineages). Clade 1 on the D2 tree is homogenous and reflects Clade 1 on the COI tree; it consists of WCM populations from wheat in Poland and South America and mites from rescuegrass in Australia, and could be concluded to represent a putative species. Moreover, on the ITS tree, wheat-associated populations from South America and Poland also formed a well supported clade. In contrast to 
Table 7. Loadings of the first three linear discriminants for morphometric data performed on six groups of Aceria tosichella and one group of Aceria tulipae corresponding to the genetic clades obtained by molecular analysis of the COI gene

\begin{tabular}{lrrr}
\hline Morphological trait & LD1 & LD2 & LD3 \\
\hline Total body length & 0.34 & -0.32 & 0.12 \\
Chelicerae length & 0.84 & 0.16 & 0.08 \\
Gnathosoma length & 0.85 & 0.09 & -0.29 \\
Prodorsal shield length & 0.72 & 0.34 & 0.13 \\
Prodorsal shield width & 0.25 & -0.52 & -0.30 \\
Length of seta $s c$ & 0.65 & 0.07 & -0.32 \\
Distance between setae $s c$ & 0.52 & 0.23 & -0.22 \\
Number of dorsal annuli & 0.83 & -0.24 & 0.28 \\
Number of ventral annuli & 0.81 & -0.03 & -0.38 \\
Length of seta $d$ & 0.64 & -0.46 & -0.06 \\
Distance between setae $d$ & 0.57 & 0.06 & 0.09 \\
Length of seta $e$ & 0.07 & -0.74 & -0.21 \\
Distance between setae $e$ & 0.60 & 0.22 & 0.15 \\
Length of seta $f$ & 0.62 & -0.33 & -0.21 \\
Distance between setae $f$ & 0.65 & 0.35 & -0.15 \\
Genital shield length & 0.73 & -0.12 & 0.08 \\
Genital shield width & 0.77 & -0.09 & 0.07 \\
Length of seta $3 a$ & 0.29 & -0.47 & -0.09 \\
Distance between setae $3 a$ & 0.68 & 0.25 & 0.24 \\
Number or ribs on epigynium & -0.05 & 0.38 & 0.20 \\
Distance between setae $1 b$ & 0.52 & 0.35 & 0.19 \\
Distance between setae $1 a$ & 0.68 & 0.29 & 0.17 \\
Distance between setae $2 a$ & 0.68 & 0.19 & 0.13 \\
Length of tibia I & 0.37 & 0.25 & -0.27 \\
Length of tarsus I & 0.58 & -0.13 & -0.35 \\
Length of solenidion I & 0.67 & -0.27 & -0.35 \\
Length of empodium I & 0.45 & 0.13 & -0.20 \\
Length of tibia II & 0.37 & 0.25 & -0.20 \\
Length of tarsus II & 0.64 & 0.07 & -0.27 \\
Length of solenidion II & 0.62 & -0.15 & -0.21 \\
Length of empodium II & 0.42 & 0.09 & -0.29 \\
Length of genual seta $l^{\prime}$ I & 0.32 & 0.22 & -0.57 \\
Length of genual seta $l^{\prime}$ II & 0.74 & 0.25 & -0.27 \\
Length of tarsal seta $f t^{\prime}$ I & 0.64 & -0.10 & -0.19 \\
Length of tarsal seta $f t^{\prime}$ I & 0.61 & -0.26 & -0.16 \\
Length of tarsal seta $f t^{\prime}$ II & 0.37 & -0.29 & -0.23 \\
Length of tarsal seta $f t^{\prime}$ II & 0.63 & -0.08 & -0.26 \\
Length of tibial seta $l^{\prime}$ I & 0.43 & 0.04 & -0.53 \\
\% of between-group variance & 58.6 & 18.1 & 12.3 \\
\hline & & &
\end{tabular}

the observed delineation within the quackgrass populations in Poland on the basis of COI sequences, no variation was observed within the D2 sequences in quackgrass-associated mites, which grouped into one homogenous Clade 2. Other genotypes of the D2 region are grouped in the third non-homogenous clade; however, these slowly evolving genes (Lee and O'Foighil 2004) were not able to resolve the relationships among these sequences, and the nesting of A. tulipae within them should be emphasised. The divergences in the $\mathrm{D} 2$ region between clades $(0.4-0.6 \%)$ were lower compared with the distances between clades and the outgroup A. eximia $(\geq 2.0 \%)$. Studies of the same region in other invertebrates have revealed greater values of divergence in the $\mathrm{D} 2$ region among species, e.g. $7.5 \%$ in water mites (Martin et al. 2010), 2.0-19.2\% in Hymenopteran parasitoids (Babcock et al. 2001; Manzari et al. 2007) and 2.1\% in Anopheles
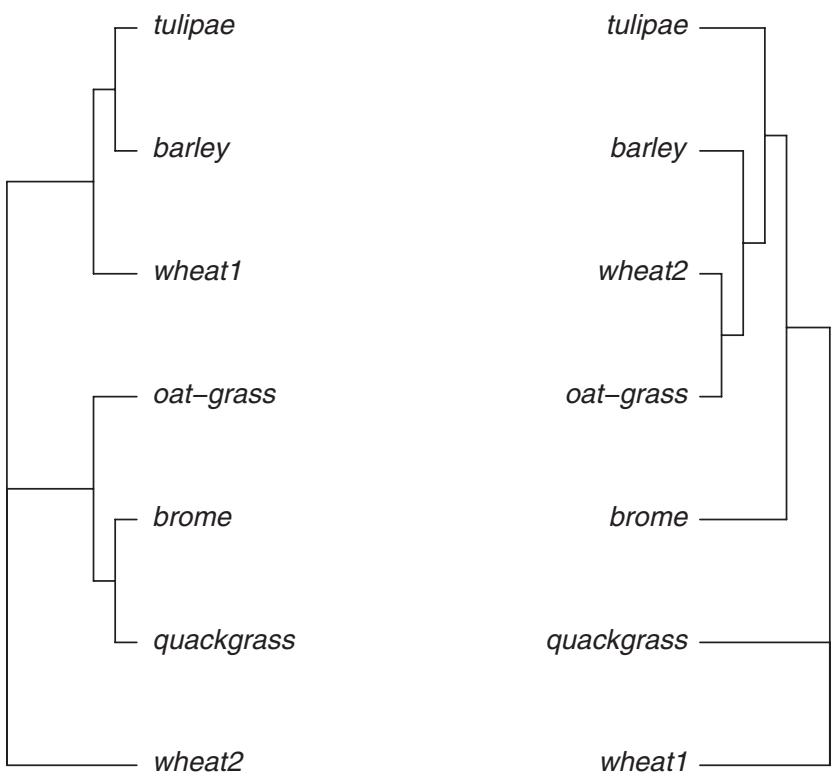

Fig. 7. Comparison of maximum-likelihood tree of the cytochrome c oxidase subunit I (only populations for which morphometric data were available are included) (left) with that obtained using squared Mahalanobis distance calculated for morphometric data (right).

culicifacies complex (Raghavendra et al. 2009). However, recent studies have indicated that two species of eriophyoid mites, Abacarus hystrix (Nalepa) and A. lolii Skoracka, for which both pre- and postzygotic reproductive barriers have been demonstrated (Skoracka 2008), exhibit a $0.2 \%$ sequence divergence in the $\mathrm{D} 2$ region, which suggests that the divergence of both species is a relatively recent event (Skoracka and Dabert 2010). The nuclear ribosomal sequences are known to be much more conserved than the COI, so closely related species often possess $28 \mathrm{~S}$ rDNA that are identical or nearly so (Lee and O'Foighil 2004). Thus, divergences in the D2 region between the WCM clades could be interpreted as interspecies, as the divergences were two- or three-fold greater than those between the Abacarus species.

The nuclear ITS region indicated the existence of two divergent lineages within the WCM. Within Clade 1, three internal lineages had split off. The Subclade 1B on the ITS tree is homogenous and reflects Clade 1 on each of the COI and D2 trees (with one exception: no ITS sequence from rescuegrass in Australia was obtained). Another consistency is between Subclade 1A on the ITS tree and Clade 2 on the D2 tree, which consist of WCM populations from quackgrass in Poland. Other genotypes of the ITS region are grouped in Clade 2, which also includes $A$. tulipae. This resolution is similar to Clade 3 on the D2 tree, although with one exception: the ITS Clade 2 does not contain brome-associated mites from Poland in contrast to D2 Clade 3. The nuclear ITS region is generally known to evolve rapidly (e.g. Harris and Crandall 2000) and has been commonly used to infer phylogeny among closely related taxa. Ectoparasite mites of the genus Dermanyssus revealed a divergence at the species level of 2-9\% (Roy et al. 2010). The ITS2 sequence divergence among closely related species of the genus Tetranychus ranges from $1.3 \%$ to $1.9 \%$ (Navajas et al. 
1994, 1998). Ben-David et al. (2007) effectively discriminated between 16 different species from nine genera of Tetranychidae using ITS2 sequences and established a $2 \%$ threshold for species diagnosis. The low ITS divergence within different species complexes suggests a recent separation of the lineages. For example, this ITS divergence was $\leq 1.17 \%$ between species belonging to the neotropical Anopheles albitarsis complex (Li and Wilkerson 2007) and $\leq 3.5 \%$ among cryptic species of the monogean ectoparasite Gyrodactylus (Bueno-Silva et al. 2011). Finally, Carew et al. (2009) demonstrated that the WCM in Australia consists of two species separated by an ITS1 sequence divergence of $1.4 \%$. Thus, the value of the ITS divergence of $\sim 2 \%$ can be interpreted as discriminating very recent lineages within the WCM, as explored in this study.

All DNA sequences included in this study exhibited high genetic differentiation within WCM, and they also indicated paraphyly of WCM with respect to its sister species A. tulipae. Moreover, some inconsistency between the mitochondrial and nuclear analyses was found, e.g. one sample of quackgrassassociated mites in Poland (ER-POLa) shared a mitochondrial lineage with sister species $A$. tulipae (the divergence between ER-POLa and A. tulipae haplotypes was 0.2). The nuclear genotypes obtained from this sample (both ITS and D2) were distinctly different from that of $A$. tulipae and were identical to other quackgrass-originating samples (viz. ER-POLb and ER-POLc). This incongruence suggests that introgressive hybridisation might have occurred between quackgrassassociated mites and $A$. tulipae, if these species might have met in sympatry. However, ecological isolation due to different host plant associations observed for quackgrassinhabiting WCM and Alliaceae-inhabiting A. tulipae may suggest that hybridisation is not possible. Therefore, the observed discrepancy between the mtDNA and nuclear genotypes may be a product of incomplete lineage sorting following recent speciation (Funk and Omland 2003; Pollard et al. 2006).

In a PCA analysis, we failed to clearly distinguish between populations of WCM. Although some populations, such as those from wheat in South America, were shown to be more clustered than others, all populations overlapped morphologically. This finding suggests that there are no distinct morphological traits that can be used to differentiate mites originating from different host plants or geographical localities and explains why the WCM complex has remained undetected for such a long time. Although LDA (which aimed to determine morphometric differences among the WCM genetic clades disclosed by the mtDNA COI region) was in most cases able to accurately classify specimens into given clades, it also did not clearly separate all of the clades. Moreover, we did not notice any clear concordance between the genetic and morphological relationships among the clades. The differences (although not discontinuous) between some of the populations and clades were attributed mostly to the shape and elongation of the body and prodorsal shield and to the length of the setae. The most morphologically distinctive mites were the brome-associated mites from Poland. When compared with the other mites, these were the smallest and had the shortest setae and the most elongated prodorsal shields. Genetically, bromeassociated mites were also the most distinctive, as they did not fit into any of the relatively homogenous clusters. Although they fell into one clade (number 3) on the nuclear D2 tree, their position was not resolved whereas, on the ITS tree, they are included within Clade 1 but did not fit into any subclade. On the combined tree, the brome-associated mites formed a single clade with one of the quackgrass haplotypes; however, the moderate support and long branches for each of the haplotypes suggests that the relationship is not very close. Another morphologically dissimilar group was the wheat-associated mites from South America. These specimens were the most robust and had the longest setae. They even differed from the other wheatassociated populations, especially those from Australia. However, the wheat-associated mites from Australia belong to a different genetic lineage (closer to the oat-grass-associated mites in Poland), and this could be the reason for their morphological separation. Moreover, the wheat-associated mites from Poland, which are genetically the same entity as mites from South America, are morphologically more similar to the Australian mites.

None of the datasets used in this study (the mitochondrial COI, nuclear ITS and D2) supported the monophyly of A. tosichella. The WCM lineages were not apparent purely on the basis of morphological features alone. Undoubtedly, other evidence, such as experimental evaluation of reproductive isolation and increased sampling throughout the entire range of $A$. tosichella, is strongly recommended to explain the relationships among the WCM lineages.

\section{The possible reasons for morphological stasis}

Aceria tosichella is a clear example that speciation is not always accompanied by exact morphological change. There may be several reasons why morphological changes might not be correlated genetically. Selection for ecological, behavioural or reproductive traits that have no observed morphological correlates might be a mechanism that promotes cryptic diversification. This diversification has been observed for myrmecophiles inhabiting ant nests, endoparasites and koinobiont parasites, which have prolonged relationships with their hosts (Schönrogge et al. 2002; Bickford et al. 2007). Eriophyoid mites are characterised by very intimate and permanent relationships with their hosts (Lindquist et al. 1996); thus the physiological adaptation of WCM populations to different host plant species is very likely.

Non-visual mating signals, such as pheromones (e.g. Crowder et al. 2010; Joyce et al. 2010) or sounds (Henry 1994; Barlow and Jones 1997; Burton and Nietsch 2010), are often used to discriminate closely related species. Whether any kind of odour or acoustic signals could be used by eriophyoid mites to differentiate between species has not been studied thus far. Generally, behavioural observations of eriophyoid mites are scarce because of their extremely small size and structural simplicity. However, on the basis of several probes (reviewed by Michalska et al. 2010), it was hypothesised that eriophyoid females can recognise spermatophores that are deposited by males via emitted attractants. Thus, WCM females may be able to distinguish between spermatophores that are placed by conspecific and non-conspecific males. There is no evidence that eriophyoid mites are able to recognise acoustic signals. However, the possibility that they are able to vibrate their elongated bodies 
to produce signals cannot be excluded. Many insects, for example, a group of green lacewings, 'play' such substrateborne songs that maintain reproductive isolation among cryptic species (Henry and Wells 2010). That recognition of the types of signals, if any, may be used by cryptic WCM lineages to discriminate between each other, is an exciting and still uncharted area of study; its exploration could clarify many questions about the process of cryptic speciation in eriophyoid mites.

The other reason for the absence of morphological differentiation within the WCM complex may be that the separation of lineages is so recent that distinctive morphological features have not yet evolved. The values of genetic distances among the WCM clades, especially for the nuclear regions, may indicate the possibility of such recent speciation. This phenomenon has also been demonstrated for coccolithophores (Sáez and Lozano 2005).

Finally, the morphological similarity observed among the WCM lineages may be the effect of undetected morphological diversity and a lack of knowledge about discerning features that could be used to distinguish the lineages effectively. Searching for new diagnostic characteristics and innovative techniques for capturing them (e.g. SEM techniques) is strongly recommended for studies on eriophyoid mites (de Lillo et al. 2010). Sole reliance on traditional taxonomy and morphological traits may fail to recognise incipient or cryptic eriophyoid species, as has been demonstrated for WCM in this study. In such cases, DNA taxonomy and associated molecular tools are very useful for revealing the true level of diversity.

\section{WCM as an invasive pest species: implications of cryptic speciation}

The misidentification of economically important species in cryptic complexes can have serious negative consequences on parasite and pest control, as well as for the diagnosis and prevention of diseases (Bickford et al. 2007). The WCM and its transmitted viruses represent an invasive mite-virus complex that has affected cereal crops around the world and is an ongoing threat to non-affected areas (Navia et al. 2010). The discovery that the WCM may be a complex of closely related species has important implications for past, current and, most importantly, future research on these pests. Distinct species, even those that are related, may differ in traits such as host specificity, life history, host colonisation ability, pesticide resistance, susceptibility to resistance genes used in cereal breeding and virus transmission. Further studies are needed to determine the vector potential of various WCM lineages throughout their ranges and to explain the plant-mite-vector relationships. Finally, in this study, we have presented information that indicates that some WCM lineages are strictly specific to a single host plant species while others can attack a range of host plants. Therefore, it would be important to devise a technique that allows the rapid differentiation between different lineages of WCM and thereby provide a new diagnostic tool for quarantine officers to use that will help limit the spread of these mites to new environments.

\section{Conclusions}

In our study, the detection of well supported genetic clades, along with various gene fragments, the amount of sequence variation and the clear gap between intra- and interclade divergences, support the hypothesis that the WCM is a species complex that also includes the Alliaceae-associated eriophyoid mite, A. tulipae. Although there are well defined morphological differences between $A$. tulipae and populations of A. tosichella, boundaries based on morphology are blurred within the WCM complex, and no diagnostic characteristics for the discrimination between WCM lineages can be proposed. This complex comprises at least two but most likely more (perhaps even seven) cryptic lineages. The apparent lack of distinguishing morphological characteristics may be evidence for the recent genetic separation of species that has not yet been accompanied by respective morphological changes. Some of the lineages were found on only a single host plant species while others were found on more than one. Some of the lineages revealed a restricted distribution while others were found to occur on different continents. All of these findings are particularly significant because of the economic importance of the WCM as a direct plant pest and as a vector of various plant viruses.

The findings above and earlier studies that have applied DNA sequence data in order to disclose cryptic speciation within eriophyoid mites (Evans et al. 2008; Carew et al. 2009; Skoracka and Dabert 2010) may impair our knowledge of biodiversity within the Eriophyoidea superfamily. The true number of eriophyoid species is likely to be far greater than has been previously estimated on the basis of host plant species richness and the delineation of mite species based on purely morphological grounds (Amrine et al. 2003). The existence of cryptic species within such an economically important group of plant mite parasites may have serious implications within the field of plant protection, especially for monitoring of these pests and the viruses they transmit.

Our results provide an excellent platform for further detailed work. It would be of great scientific value and agricultural importance to undertake the following studies: searching for other cryptic forms within the WCM complex, which is considered to be widespread across the world; providing more detailed examination of the morphological characteristics that may distinguish different genetic lineages; inspecting other traits that could be used to differentiate between these cryptic forms, such as ecological, physiological or behavioural characteristics; and applying other molecular markers to help resolve the phylogenetic relationships among the WCM lineages. Finally, a detailed revision of the taxonomy and nomenclature of the WCM species complex should be considered in the future. However, a more comprehensive analysis of the genetic and ecological variation within the WCM throughout its host range and geographical distribution is a first priority.

\section{Acknowledgements}

We sincerely thank Paulo Roberto da Silva Pereira, Douglas Lau (Brazil) and Serge Kreiter (France) for their help with sampling; Katarzyna Zawadzka and Urszula Baraniak (AMU, Poland) for help with laboratory work; the Brazil National Council for Scientific and Technological Development (CNPq) for providing support for research activities and author fellowships in Brazil (call CNPq/MAPA/SDA $\mathrm{N}^{\circ}$ 064/2008), four anonymous reviewers and the journal editor for helpful, valuable and encouraging remarks on the manuscript. The study components conducted by AS, LK, MD and WS 
(Poland) were supported by the Polish Ministry of Science and Higher Education (grant no. NN 303089434).

\section{References}

Amrine, J. W., Jr (2003). Catalog of the Eriophyoidea. A working catalog of the Eriophyoidea of the world. Ver. 1.0. Available online at http://insects. tamu.edu/research/collection/hallan/acari/eriophyidae [Accessed on 1 June 2011].

Amrine, J. W., Jr, and Manson, D. C. M. (1996). Preparation, mounting and descriptive study of eriophyoid mites. In 'Eriophyoid Mites - Their Biology, Natural Enemies and Control'. (Eds E. E. Lindquist, M. W. Sabelis and J. Bruin.) pp. 383-396. (Elsevier Science Publishers: Amsterdam.)

Amrine, J. W., Jr, Stasny, T. A. H., and Flechtmann, C. H. W. (2003). 'Revised Keys to the World Genera of the Eriophyoidea (Acari: Prostigmata).' (Indira Publishing House: West Bloomfield, MI.)

Anderson, D. L., and Morgan, M. J. (2007). Genetic and morphological variation of bee-parasitic Tropilaelaps mites (Acari: Laelapidae): new and re-defined species. Experimental \& Applied Acarology 43, 1-24. doi:10.1007/s10493-007-9103-0

Anisimova, M., and Gascuel, O. (2006). Approximate likelihood-ratio test for branches: a fast, accurate, and powerful alternative. Systematic Biology 55, 539-552. doi:10.1080/10635150600755453

AQIS (2000). Import risk analysis for the importation of bulk maize (Zea mays L.) from the United States of America. Australian Quarantine and Inspection Service, Department of Agriculture, Fisheries and Forestry, Australia. Available online at http://www.daff.gov.au/_data/assets/pdf_ file/0012/20901/rev_dft_ira_maize.pdf [Accessed on 25 May 2011].

Armstrong, K. F., and Ball, S. L. (2005). DNA barcodes for biosecurity: invasive species identification. Philosophical Transactions of the Royal Society B 360, 1813-1823. doi:10.1098/rstb.2005.1713

Astrin, J. J., and Stüben, P. E. (2008). Phylogeny in cryptic weevils: molecules, morphology and new genera of western Palaearctic Cryptorhynchinae (Coleoptera: Curculionidae). Invertebrate Systematics 22, 503-522. doi:10.1071/IS07057

Babcock, C. S., Heraty, J. M., De Barro, P. J., Driver, F., and Schmidt, S. (2001). Preliminary phylogeny of Encarsia Förster (Hymenoptera: Aphelinidae) based on morphology and 28S rDNA. Molecular Phylogenetics and Evolution 18, 306-323. doi:10.1006/mpev.2000.0875

Barlow, K. E., and Jones, G. (1997). Function of pipistrelle social calls: field data and a playback experiment. Animal Behaviour 53, 991-999. doi:10.1006/anbe.1996.0398

Ben-David, T., Melamed, S., Gerson, U., and Morin, S. (2007). ITS2 sequences as barcodes for identifying and analyzing spider mites (Acari: Tetranychidae). Experimental \& Applied Acarology 41, 169-181. doi:10.1007/s10493-007-9058-1

Bickford, D., Lohman, D. J., Sodhi, N. S., Ng, P. K. L., Meier, R., Winker, K., Ingram, K. K., and Das, I. (2007). Cryptic species as a window on diversity and conservation. Trends in Ecology \& Evolution 22, 148-155. doi:10.1016/j.tree.2006.11.004

Blair, C. P., Abrahamson, W. G., Jackman, J. A., and Tyrrell, L. (2005). Cryptic speciation and host-race formation in a purportedly generalist tumbling flower beetle. Evolution 59, 304-316.

Blanquer, A., and Uriz, M. (2008). "A posteriori” searching for phenotypic characters to describe new cryptic species of sponges revealed by molecular markers (Dictyonellidae: Scopalina). Invertebrate Systematics 22, 489-502. doi:10.1071/IS07004

Bueno-Silva, M., Boeger, W. A., and Pie, M. R. (2011). Choice matters: incipient speciation in Gyrodactylus corydori (Monogenoidea: Gyrodactylidae). International Journal for Parasitology 41, 657-667. doi:10.1016/j.ijpara.2011.01.002
Burton, J. A., and Nietsch, A. (2010). Geographical variation in duet songs of Sulawesi tarsiers: evidence for new cryptic species in south and southeast Sulawesi. International Journal of Primatology 31, 1123-1146. doi:10.1007/s10764-010-9449-8

Calcagno, V., Bonhomme, V., Thomas, Y., Singer, M. C., and Bourguet, D. (2010). Divergence in behaviour between the European corn borer, Ostrinia nubilalis, and its sibling species Ostrinia scapulalis: adaptation to human harvesting? Proceedings. Biological Sciences 277, 2703-2709. doi:10.1098/rspb.2010.0433

Carew, M., Schiffer, M., Umina, P., Weeks, A., and Hoffmann, A. (2009). Molecular markers indicate that the wheat curl mite, Aceria tosichella Keifer, may represent a species complex in Australia. Bulletin of Entomological Research 99, 479-486. doi:10.1017/S00074853080 06512

Castiglioni, E., and Navia, D. (2010). Presence of the wheat curl mite, Aceria tosichella Keifer (Prostigmata: Eriophyidae), in Uruguay. Agrociencia 14, 19-26.

Crowder, D. W., Sitvarin, M. I., and Carriére, Y. (2010). Mate discrimination in invasive whitefly species. Journal of Insect Behavior 23, 364-380. doi:10.1007/s10905-010-9219-7

Dabert, J., Ehrnsberger, R., and Dabert, M. (2008). Glaucalges tytonis sp. n. (Analgoidea, Xolalgidae) from the barn owl Tyto alba (Strigiformes, Tytonidae): compiling morphology with DNA barcode data for taxon descriptions in mites (Acari). Zootaxa 1719, 41-52.

Dabert, M., Witalinski, W., Kazmierski, A., Olszanowski, Z., and Dabert, J. (2010). Molecular phylogeny of acariform mites (Acari, Arachnida): strong conflict between phylogenetic signal and long-branch attraction artifacts. Molecular Phylogenetics and Evolution 56, 222-241. doi:10.1016/j.ympev.2009.12.020

de Lillo, E. (2001). A modified method for eriophyoid mite extraction (Acari, Eriophyoidea). International Journal of Acarology 27, 67-70. doi:10.1080/01647950108684228

de Lillo, E., Craemer, C., Amrine, J., Jr, W., and Nuzzaci, G. (2010). Recommended procedures and techniques for morphological studies of Eriophyoidea (Acari: Prostigmata). Experimental \& Applied Acarology 51, 283-307. doi:10.1007/s10493-009-9311-x

Desneux, N., Stary, P., Delebecque, C. J., Gariepy, T. D., Barta, R. J., Hoelmer, K. A., and Heimpel, G. E. (2009). Cryptic species of parasitoids attacking the soybean aphid (Hemiptera: Aphididae) in Asia: Binodoxys communis and Binodoxys koreanus (Hymenoptera: Braconidae: Aphidiinae). Annals of the Entomological Society of America 102, 925-936. doi:10.1603/008.102.0603

Drés, M., and Mallet, J. (2002). Host races in plant-feeding insects and their importance in sympatric speciation. Philosophical Transactions of the Royal Society of London, Series B 357, 471-492. doi:10.1098/rstb. 2002.1059

Duso, C., Castagnoli, M., Simoni, S., and Angeli, G. (2010). The impact of eriophyoids on crops: recent issues on Aculus schlechtendali, Calepitrimerus vitis and Aculops lycopersici. Experimental \& Applied Acarology 51, 151-168. doi:10.1007/s10493-009-9300-0

Evans, L. M., Allan, G. J., Shuster, S. M., Woolbright, S. A., and Whitham, T. G. (2008). Tree hybridization and genotypic variation drive cryptic speciation of a specialist mite herbivore. Evolution 62, 3027-3040. doi:10.1111/j.1558-5646.2008.00497.x

French, R., and Stenger, D. C. (2003). Evolution of wheat streak mosaic virus: dynamics of population growth within plants may explain limited variation. Annual Review of Phytopathology 41, 199-214. doi:10.1146/ annurev.phyto.41.052002.095559

Funk, D. J., and Omland, K. E. (2003). Species-level paraphyly and polyphyly: frequency, causes, and consequences, with insight from animal mitochondrial DNA. Annual Review of Ecology Evolution and Systematics 34, 397-423. doi:10.1146/annurev.ecolsys.34.011802. 132421 
Guindon, S., and Gascuel, O. (2003). A simple, fast, and accurate algorithm to estimate large phylogenies by maximum likelihood. Systematic Biology 52, 696-704. doi:10.1080/10635150390235520

Guindon, S., Dufayard, J. F., Lefort, V., Anisimova, M., Hordijk, W., and Gascuel, O. (2010). New algorithms and methods to estimate maximumlikelihood phylogenies: assessing the performance of PhyML 3.0. Systematic Biology 59, 307-321. doi:10.1093/sysbio/syq010

Hadi, B. A. R., Langham, M. A. C., Osborne, L., and Tilmon, K. J. (2011). Wheat streak mosaic virus on wheat: biology and management. Journal of Integrated Pest Management 2, 1-5. doi:10.1603/IPM10017

Hall, T. A. (1999). BIOEDIT: a user-friendly biological sequence alignment editor and analysis program for windows 95/98/NT. Nucleic Acids Symposium Series 41, 95-98.

Halliday, R. B., and Knihinicki, D. K. (2004). The occurrence of Aceria tulipae (Keifer) and Aceria tosichella Keifer in Australia (Acari: Eriophyidae). International Journal of Acarology 30, 113-118. doi: $10.1080 / 01647950408684378$

Halt, M. N., Kupriyanova, E. K., Cooper, S. J. B., and Rouse, G. W. (2009). Naming species with no morphological indicators: species status of Galeolaria caespitosa (Annelida: Serpulidae) inferred from nuclear and mitochondrial gene sequences and morphology. Invertebrate Systematics 23, 205-222. doi:10.1071/IS09003

Hansen, B., Adams, M., Krasnicki, T., and Richardson, A. M. M. (2001). Substantial allozyme diversity in the freshwater crayfish Parastacoides tasmanicus supports extensive cryptic speciation. Invertebrate Systematics 15, 667-679. doi:10.1071/IT00052

Harris, D. J., and Crandall, K. A. (2000). Intragenomic variation within ITS1 and ITS2 of freshwater crayfishes (Decapoda: Cambaridae): implications for phylogenetic and microsatellite studies. Molecular Biology and Evolution 17, 284-291. doi:10.1093/oxfordjournals.molbev.a026308

Harvey, T. L., Martin, T. J., Seifers, D. L., and Sloderbeck, P. E. (1995a). Adaptation of wheat curl mite (Acari: Eriophyidae) to resistant wheat in Kansas. Journal of Agricultural Entomology 12, 119-125.

Harvey, T. L., Martin, T. J., and Seifers, D. L. (1995b). Survival of five wheat curl mite Aceria tosichella Keifer (Acari: Eriophyidae) strains on mite resistant wheat. Experimental \& Applied Acarology 19, 459-463.

Harvey, T. L., Martin, T. J., and Seifers, D. L. (2002). Wheat yield reduction due to wheat curl mite (Acari: Eriophyidae) infestations. Journal of Agriculture and Urban Entomology 19, 9-13.

Hebert, P. D. N., Ratnasingham, S., and de Waard, J. R. (2003). Barcoding animal life: cytochrome $\mathrm{c}$ oxidase subunit I divergences among closely related species. Proceedings of the Royal Sociey of London B Biological Sciences 270, S96-S99. doi:10.1098/rsbl.2003.0025

Hebert, P. D. N., Penton, E. H., Burns, J. M., Janzen, D. H., and Hallwachs, W. (2004). Ten species in one: DNA barcoding reveals cryptic species in the neotropical skipper butterfly Astraptes fulgerator. Proceedings of the National Academy of Sciences of the United States of America 101, 14812-14817. doi:10.1073/pnas.0406166101

Henry, C. S. (1994). Singing and cryptic speciation in insects. Trends in Ecology \& Evolution 9, 388-392. doi:10.1016/0169-5347(94)90061-2

Henry, C. S., and Wells, M. M. (2010). Acoustic niche partitioning in two cryptic sibling species of Chrysoperla green lacewings that must duet before mating. Animal Behaviour 80, 991-1003. doi:10.1016/j.anbehav. 2010.08.021

Jeppson, L. R., Keifer, H. H., and Baker, E. W. (1975). 'Mites Injurious to Economic Plants.' (University of California Press: Berkeley, CA.)

Jesse, R., Schubart, C. D., and Klaus, S. (2010). Identification of a cryptic lineage within Potamon fluviatile (Herbst) (Crustacea: Brachyura: Potamidae). Invertebrate Systematics 24, 348-356.

Joyce, A. L., Bernal, J. S., Vinson, S. B., Hunt, R. E., Schulthess, F., and Medina, R. F. (2010). Geographic variation in male courtship acoustics and genetic divergence of populations of the Cotesia flavipes species complex. Entomologia Experimentalis et Applicata 137, 153-164. doi:10.1111/j.1570-7458.2010.01048.x
Keifer, H. H. (1938). Eriophyid Studies I. Bulletin of the Department of Agriculture State of California 27, 181-206.

Keifer, H. H. (1969). Eriophyid Studies C-3. Agricultural Research Service, United States Department of Agriculture 1-24.

Kimura, M. (1980). A simple method for estimating evolutionary rate of base substitutions through comparative studies of nucleotide sequences. Journal of Molecular Evolution 16, 111-120. doi:10.1007/BF01731581

Lee, T., and O'Foighil, D. (2004). Hidden Floridian biodiversity: mitochondrial and nuclear gene trees reveal four cryptic species within the scorched mussel, Brachidontes exustus, species complex. Molecular Ecology 13, 3527-3542. doi:10.1111/j.1365-294X.2004.02337.x

Li, C., and Wilkerson, R. C. (2007). Intragenomic rDNAITS2 variation in the neotropical Anopheles (Nyssorhynchus) albitarsis complex (Diptera: Culicidae). The Journal of Heredity 98, 51-59. doi:10.1093/jhered/ es1037

Lindquist, E. E., Sabelis, M. W., and Bruin, J. (1996). 'Eriophyoid Mites Their Biology, Natural Enemies and Control.' (Elsevier Science Publishers: Amsterdam.)

Lynch, M., Koskella, B., and Schaack, S. (2006). Mutation pressure and the evolution of organelle genomic architecture. Science 311, 1727-1730. doi:10.1126/science. 1118884

Manzari, S., Polaszek, A., Belshaw, R., and Quicke, D. L. J. (2007). Morphometric and molecular analysis of the Encarsia inaron speciesgroup (Hymenoptera: Aphelinidae), parasitoids of whiteflies (Hemiptera: Aleyrodidae). Bulletin of Entomological Research 92, 165-176.

Martin, P., Dabert, M., and Dabert, J. (2010). Molecular evidence for species separation in the water mite Hygrobates nigromaculatus Lebert, 1879 (Acari, Hydrachnidia): evolutionary consequences of the loss of larval parasitism. Aquatic Sciences 72, 347-360. doi:10.1007/s00027-0100135-x

Michalska, K., Skoracka, A., Navia, D., and Amrine, J. W. (2010). Behavioural studies on eriophyoid mites: an overview. Experimental \& Applied Acarology 51, 31-59. doi:10.1007/s10493-009-9319-2

Murray, G. M., Knihinicki, D. K., Wratten, K., and Edwards, J. (2005). Wheat streak mosaic and the wheat curl mite. NSW Department of Primary Industries, Orange, New South Wales, Australia. Primefact 99.

Navajas, M., Gutierrez, J., Bonato, O., Bolland, H. R., and MapangouDivassa, S. (1994). Intraspecific diversity of the cassava green mite Mononychellus progresivus (Acari: Tetranychidae) using comparisons of mitochondrial and nuclear ribosomal DNA sequences and crossbreeding. Experimental \& Applied Acarology 18, 351-360. doi:10.1007/ BF00116316

Navajas, M., Lagnel, J., Gutierrez, J., and Boursot, P. (1998). Species-wide homogeneity of nuclear ribosomal ITS2 sequences in the spider mite Tetranychus urticae contrasts with extensive mitochondrial COI polymorphism. Heredity 80, 742-752. doi:10.1046/j.1365-2540.1998. 00349.x

Navia, D., De Moraes, G. J., Roderick, G., and Navajas, M. (2005). The invasive coconut mite Aceria guerreronis (Acari: Eriophyidae): origin and invasion sources inferred from mitochondrial (16S) and nuclear (ITS) sequences. Bulletin of Entomological Research 95, 505-516. doi:10.1079/BER2005382

Navia, D., Truol, G., Mendonca, R. S., and Sagadin, M. (2006). Aceria tosichella Keifer (Acari: Eriophyidae) from wheat streak mosaic virus-infected wheat plants in Argentina. International Journal of Acarology 32, 189-193. doi:10.1080/01647950608684460

Navia, D., Ochoa, R., Welbourn, C., and Ferragut, F. (2010). Adventive eriophyoid mites: a global review of their impact, pathways, prevention and challenges. Experimental \& Applied Acarology 51, 225-255. doi:10.1007/s10493-009-9327-2

Navia, D., Mendonca, R. S., Skoracka, A., Szydło, W., Knihinicki, D., Hein, G. L., Pereira, P. L., Truol, G., and Douglas, L. (2012). Wheat curl mite, Aceria tosichella, and transmitted viruses: an expanding pest complex affecting cereal crops. Experimental \& Applied Acarology, in press. 
Nicholas, K. B., and Nicholas, H. B., Jr (1997). GeneDoc: a tool for editing and annotating multiple sequence alignments. Pittsburgh Supercomputing Center's National Resource for Biomedical Supercomputing, ver. 2.7.000. Available online at http://www.nrbsc. org/downloads [Accessed on 25 March 2011].

Oldfield, G. N., and Proeseler, G. (1996). Eriophyoid mites as vectors of plant pathogens. In 'Eriophyoid Mites - Their Biology, Natural Enemies and Control'. (Eds E. E. Lindquist, M. W. Sabelis and J. Bruin.) pp. 259-273. (Elsevier Science Publishers: Amsterdam.)

Pfenninger, M., and Schwenk, K. (2007). Cryptic animal species are homogeneously distributed among taxa and biogeographical regions. BMC Evolutionary Biology 7, 121. doi:10.1186/1471-2148-7-121

Pollard, D. A., Iyer, V. N., Moses, A. M., and Eisen, M. B. (2006). Widespread discordance of gene trees with species tree in Drosophila: evidence for incomplete lineage sorting. PLOS Genetics 2(10), e173. doi:10.1371/ journal.pgen.0020173

Posada, D. (2008). jModelTest: phylogenetic model averaging. Molecular Biology and Evolution 25, 1253-1256. doi:10.1093/molbev/ msn083

Pringle, A., Baker, D. M., Platt, J. L., Wares, J. P., Latge, J. P., and Taylor, J. W. (2005). Cryptic speciation in the cosmopolitan and clonal human pathogenic fungus Aspergillus fumigatus. Evolution 59, 1886-1899.

R Development Core Team (2010). 'R: A Language and Environment for Statistical Computing.' R Foundation for Statistical Computing, Vienna, Austria. Available online at http://www.R-project.org [Accessed on 20 June 2011].

Rach, J., DeSalle, R., Sarkar, I. N., Schierwater, B., and Hadrys, H. (2008). Character-based DNA barcoding allows discrimination of genera, species and populations in Odonata. Proceedings. Biological Sciences 275, 237-247. doi:10.1098/rspb.2007.1290

Raghavendra, K., Cornel, A. J., Reddy, B. P. N., Collins, F. H., Nanda, N., Chandra, D., Verma, V., Dash, A. P., and Subbarao, S. K. (2009). Multiplex PCR assay and phylogenetic analysis of sequences derived from $\mathrm{D} 2$ domain of $28 \mathrm{~S}$ rDNA distinguished members of the Anopheles culicifacies complex into two groups, $\mathrm{A} / \mathrm{D}$ and $\mathrm{B} / \mathrm{C} / \mathrm{E}$. Infection, Genetics and Evolution 9, 271-277. doi:10.1016/j.meegid. 2008.12.007

Ronquist, F., and Huelsenbeck, J. P. (2003). MrBayes 3: Bayesian phylogenetic inference under mixed models. Bioinformatics (Oxford, England) 19, 1572-1574. doi:10.1093/bioinformatics/btg180

Roy, L., Dowling, A. P. G., Chauve, C. M., and Buronfosse, T. (2010). Diversity of phylogenetic information according to the locus and the taxonomic level: an example from a parasitic mesostigmatid mite genus. International Journal of Molecular Sciences 11, 1704-1734. doi:10.3390/ijms11041704

Sáez, A. G., and Lozano, E. (2005). Body doubles. Nature 433, 111. doi:10.1038/433111a

Sánchez-Sánchez, H., Henry, M., Cárdenas-Soriano, E., and AlvizoVillasana, H. (2001). Identification of Wheat streak mosaic virus and its vector Aceria tosichella Keifer in Mexico. Plant Disease 85, 13-17. doi:10.1094/PDIS.2001.85.1.13

Schönrogge, K., Barr, B., Wardlaw, J. C., Napper, E., Gardner, M. G., Elmes, G. W., and Thomas, J. A. (2002). When rare species become endangered: cryptic speciation in myrmecophilous hoverflies. Biological Journal of the Linnean Society. Linnean Society of London 75, 291-300. doi:10.1111/j.1095-8312.2002.tb02070.x

Seifers, D. L., Martin, T. J., Harvey, T. J., Fellers, J. P., Stack, J. P., RybaWhite, M., Haber, S., Krokhin, O., Spicer, V., Lovat, N., Yamchuk, A., and Standing, K. G. (2008). Triticum mosaic virus: a new virus isolated from wheat in Kansas. Plant Disease 92, 808-817. doi:10.1094/PDIS-92$5-0808$
Seifers, D. L., Martin, T. J., Harvey, T. L., Fellers, J. P., and Michaud, J. P. (2009). Identification of the wheat curl mite as the vector of triticum mosaic virus. Plant Disease 93, 25-29. doi:10.1094/PDIS-93-1-0025

Skoracka, A. (2004). Eriophyoid mites from grasses in Poland (Acari: Eriophyoidea). Genus (Suppl.), 1-205.

Skoracka, A. (2008). Reproductive barriers between populations of the cereal rust mite Abacarus hystrix confirm their host specialization. Evolutionary Ecology 22, 607-616. doi:10.1007/s10682-007-9185-5

Skoracka, A., and Dabert, M. (2010). The cereal rust mite Abacarus hystrix (Acari: Eriophyoidea) is a complex of species: evidence from mitochondrial and nuclear DNA sequences. Bulletin of Entomological Research 100, 263-272. doi:10.1017/S0007485309990216

Skoracka, A., Smith, L., Oldfield, G., Cristofaro, M., and Amrine, J. W. (2010). Host-plant specificity and specialization in eriophyoid mites and their importance for the use of eriophyoid mites as biocontrol agents of weeds. Experimental \& Applied Acarology 51, 93-113. doi:10.1007/ s10493-009-9323-6

Smith, M. A., Woodley, N. E., Janzen, D. H., Hallwachs, W., and Hebert, P. D. N. (2006). DNA barcodes reveal cryptic host-specificity within the presumed polyphagous members of a genus of parasitoid flies (Diptera: Tachinidae). Proceedings of the National Academy of Sciences of the United States of America 103, 3657-3662. doi:10.1073/pnas.0511318103

Sonnenberg, R., Nolte, A. W., and Tautz, D. (2007). An evaluation of LSU rDNA D1-D2 sequences for their use in species identification. Frontiers in Zoology 4, 6. doi:10.1186/1742-9994-4-6

Spencer, H. G., Marshall, B. A., and Waters, J. M. (2009). Systematics and phylogeny of a new cryptic species of Diloma Philippi (Mollusca: Gastropoda: Trochidae) from a novel habitat, the bull kelp holdfast communities of southern New Zealand. Invertebrate Systematics 23, 19-25. doi:10.1071/IS08030

Stephan, D., Moeller, I., Skoracka, A., Ehrig, F., and Maiss, E. (2008). Eriophyid mite transmission and host range of a Brome streak mosaic virus isolate derived from a full-length cDNA clone. Archives of Virology 153, 181-185. doi:10.1007/s00705-007-1065-3

Stireman, J. O., III, Nason, J. D., and Heard, S. B. (2005). Host-associated genetic differentiation in phytophagous insects: general phenomenon or isolated exceptions? Evidence from a goldenrod-insect community. Evolution 59, 2573-2587.

Styer, W. E., and Nault, L. R. (1996). Corn and grain plants. In 'Eriophyoid Mites - Their Biology, Natural Enemies and Control'. (Eds E. E. Lindquist, M. W. Sabelis and J. Bruin.) pp. 611-618. (Elsevier Science Publishers: Amsterdam.)

Sukhareva, S. (1983). New species of eriophyid mites of the genus Aceria Keif. (Acariformes, Tetrapodili) living on grasses. Entomologiceskoe Obozrenie 62, 391-395.

Tamura, K., Peterson, D., Peterson, N., Stecher, G., Nei, M., and Kumar, S. (2011). MEGA5: molecular evolutionary genetics analysis using maximum likelihood, evolutionary distance, and maximum parsimony methods. Molecular Biology and Evolution 28, 2731-2739. doi:10.1093/ molbev/msr121

Thompson, J. D., Higgins, D. G., and Gibson, T. J. (1994). CLUSTAL W: improving the sensitivity of progressive multiple sequence alignment through sequence weighting, position-specific gap penalties and weight matrix choice. Nucleic Acids Research 22, 4673-4680. doi:10.1093/nar/ 22.22.4673

Tixier, M.-S., Kreiter, S., Croft, B. A., and Cheval, B. (2008). Kampimodromus aberrans (Acari: Phytoseiidae) from the USA: morphological and molecular assessment of its density. Bulletin of Entomological Research 98, 125-134. doi:10.1017/S00074853070 05457 